\title{
Education for Sustainable Development: Evolution and Perspectives: A Bibliometric Review of Research, 1992-2018
}

\author{
Gabriela Grosseck ${ }^{1, *}$, Laurențiu Gabriel Țîru ${ }^{2}$ and Ramona Alice Bran ${ }^{1}$ \\ 1 Department of Psychology, West University of Timișoara, 4 Bd. Vasile Pârvan, 300223 Timișoara, Romania; \\ ramona.bran@e-uvt.ro \\ 2 Department of Sociology, West University of Timișoara, 4 Bd. Vasile Pârvan, 300223 Timișoara, Romania; \\ laurentiu.tiru@e-uvt.ro \\ * Correspondence: gabriela.grosseck@e-uvt.ro
}

Received: 24 September 2019; Accepted: 31 October 2019; Published: 3 November 2019

\begin{abstract}
In recent years, the interest in research concerning Education for Sustainable Development (ESD) has grown considerably. Therefore, a thorough (re)evaluation of this field and its challenges is highly necessary and can help us better understand the diversity of ESD approaches and the ways in which various scholars, countries, institutions, or universities reacted through research and scientific publications to the study of ESD. Using a bibliometric approach, we analyzed 1813 papers on the subject, indexed by the Web of Science, between 1992 and 2018. The main findings increased our understanding of the ESD domain: we identified vital research, landmark studies in the development of the field, critical past contributions, emerging trends, and potentially transformative ideas. The number of publications, authors, and journals has increased, proving that ESD has gained momentum over the period examined in the study. Similarly, there are more and more works written in collaboration by people (scholars, researchers, etc.) from different parts and cultures of the world, indicating that publishing on ESD is like a legacy to international efforts to bring this area of inquiry into the mainstream. Finally, the study illustrates two main research directions for the entire timespan: integration of education into sustainable development and of sustainable development into education.
\end{abstract}

Keywords: education for sustainable development; sustainability education; education for sustainability; bibliometric review

\section{Introduction}

In recent years, numerous studies [1-10] have shown that the interest in research concerning Education for Sustainable Development (ESD) has grown considerably. As it expands rapidly, this sector is becoming more visible and significant in a global world affected by serious environmental issues and by growing social, economic, and political inequality. Hence, sustainable development is a real challenge for our society.

Climate change, global warming, depletion of natural resources, desertification, pollution of bodies of water and air, high carbon emissions, food shortages, and other threats to our world's future demand more sustainable societies, lifestyles, and economies.

There are numerous definitions for Sustainable Development (SD), but the best known and generally-accepted one belongs to the Brundtland Commission: "sustainable development seeks to meet the needs and aspirations of the present without compromising the ability to meet those of the future" [11] (p. 39). The European Commission [12] also explains the role of SD: "it provides a comprehensive approach bringing together economic, social and environmental considerations in ways that mutually reinforce each other". 
In 2015, all United Nations Organization (UN) member states adopted Agenda 2030 for SD. It represents the social and economic contract of the 21st Century, the new global sustainable development framework that redefines the way in which the international community works together to ensure a different future for people and planet Earth [13]. Agenda 2030 comprises 17 Sustainable Development Goals (SDG). These objectives are global, generally applicable, and interconnected, although each of them has its own targets (169 in all). The SDGs cover a wide range of issues connected to social and economic development, including, among others, combating poverty and famine, ensuring health and education, sustainable management of natural resources, climate change, gender equality, cultural diversity, rural and urban development, social justice, security, human rights, peace, ethics, civic responsibility at the local, regional, and global level, the economy, democracy, and governance.

Several paths towards achieving SD exist (e.g., sustainable agriculture, sustainable consumption, etc.). One of these paths is education, a fundamental tool for achieving a more sustainable world, the essence of Sustainable Development Goal 4 (SGD4). It is true that, on its own, education does not bring a more sustainable future. However, it is equally true that, without education for sustainable development, we cannot manage to create a sustainable future [14].

The turning point for Education for Sustainable Development (ESD) was in 1992, during the Rio de Janeiro Earth Summit, when the UN elaborated Agenda 21, an action plan for the 21st Century oriented towards sustainable development. Agenda 21 recognizes education as an essential path towards a more sustainable future [15]. Since then, the critical role that ESD plays in coping with sustainability has been recognized worldwide [16].

The world summit in Johannesburg (2002) proclaimed the period between 2005 and 2014 the Decade of Education for Sustainable Development (DESD). During this decade, UNESCO staged a worldwide effort to foster ESD and reshape curricula. The follow-up program to the Decade of ESD is "The Global Action Programme" (GAP) on ESD, which started in 2015 and comes to an end in 2019. With the objective of scaling up action on ESD, in all areas of education and at all levels and disciplines, GAP contributes substantially to the 2030 agenda.

Essentially, ESD describes the practice of teaching for sustainability. As Veiga Ávila and his colleagues emphasized "it is a vital and eternal struggle that challenges people, institutions and society" [7] (p. 109). Its main aim is to "endow" the new generation with leadership and management abilities, as well as with the necessary knowledge, skills, attitudes, and values that are required in order to forge a sustainable future [17] (p. 954).

According to the UNESCO definition, ESD is a collection of diverse disciplines, like climate change, the management of the effects of social and economic changes, environmental economics, and so on. In order to understand the complexity of SD issues, interdisciplinarity is the key factor [18]. In this sense, ESD can be seen as a holistic approach, involving the integration of major sustainable development issues into all teaching and learning strategies. Furthermore, a structured, coherent language is important [19]. As shown by Pauw et al. [16], ESD focuses on participation, cooperation, and engagement in teaching and learning. These methods can generate change in people's mentalities and can influence their attitudes and behaviors, while, at the same time, enabling them to cope with the challenges of SD. Consequently, ESD is a means of promoting key competencies for sustainability, such as critical thinking, systematic thinking, self-awareness, problem solving, etc.

Van Poeck and Loones gave a more pragmatic definition of ESD. According to them, it "is learning to think about and work towards a livable world, now and in the future, for ourselves and for others, here and elsewhere on the planet" [20] (p. 4). Lambrechts and Hindson corroborated this view and clarified which pivotal sustainability issues we have to consider, now and in the future. Moreover, because everything is changing and the future is uncertain, they emphasized the fact that "ESD needs to evolve itself in order to be able to provide skills and competences that enable people to cope with this complexity and uncertainty" [21] (p. 7).

Following UNESCO's recommendation to carry out more research on ESD, we have witnessed a trend of explosive growth and great progress in many fields. However, it is still difficult today to address 
UNESCO's challenge in its full complexity. Despite the abundance of research initiatives on ESD, there still is a need for further research on particular issues, for example: designing original educational approaches, tools, and sustainable policies to achieve SD [2,22,23]; the extent (and challenges) to which it is implemented in classrooms [24,25]; identifying the critical factors to raise students' sustainability consciousness [5,26]; exploring new learning environments and methodologies (Massive Open Online Courses - MOOCs, flipped classroom, or serious games in sustainability) [27-30]; rethinking the curriculum in order to prepare learners for the increasing presence of technologies (such as artificial intelligence, robotics, Internet of Things, etc.) [31-33], etc.

Practically, a thorough (re)evaluation of this field and its challenges is inevitable and can help us better understand the diversity of ESD approaches, the ways in which various researchers, countries, institutions, or universities have reacted through research and scientific publications to the study of ESD, but also, as Stevenson et al. [34] states, to "critically examine the historical progression of the field, its current debates and controversies", what (and why) is still missing from the ESD research agenda, and "where that agenda might be headed".

Hence, the aim of the current review is to track down the development of ESD. By using a bibliometric approach, we are able to provide useful and up-to-date information about the features and evolution of the literature. In order to do so, we analyzed 1813 papers extracted from the Web of Science Core Collection (WoS), covering the period 1992-2018. In addition to the bibliometric indicators offered by WoS, we used the VosViewer and CiteSpace software in order to visualize the intellectual structure, conceptual dynamics, diffusion of knowledge, development over time, research trends (identifying the fast growing/popular topical areas), core authors, top journals, leading countries and institutions, the impact of collaboration, etc.

The structure of the paper is as follows: After the Introduction, we continue with the second section, which presents a literature review of the bibliometric analysis on the ESD field and delineates its domain. In the third section, we describe the methodology of the study, while in the fourth part, we analyze the data and present the results of the bibliometric analysis. The fifth section provides discussions, limitations, and suggestions for further research. In the end, we draw several conclusions.

\section{Literature Review of Bibliometric Studies on ESD}

In a broad sense, bibliometric analysis is used to obtain quantitative data regarding academic literature. More specifically, Liao et al. define it as "the cross-disciplinary science of quantitative analysis of all knowledge carriers by mathematical and statistical methods" [35] (p. 1). The main elements of a bibliometric analysis are the documents, authors, journals, references, citations, and co-citations.

Even though a bibliometric approach is not the perfect tool for all fields and in all circumstances, there are many publications that confirm the fact that bibliometric analysis is used as a tool by all scientific communities: to appraise the quality of a research field [36,37]; to evaluate the quality of a journal [38,39]; to establish a scientific portrait by looking at the activity of a researcher, or group of researchers [40,41]; to classify types of scientific networks and map scientific collaborations, on inter-institutional, national, and international levels [42,43]; to evaluate the influence of financing certain programs and/or projects on scientific production [44,45]; to set up hierarchies, by comparing one country to another, one institution in relation to a country, and even researchers and scientists in relation to their own scientific communities [6,46-48]. At the same time, bibliometric analysis can be applied to macro analyses (e.g., a country's quota in the global production of scientific literature during a given period of time), as well as to micro studies (e.g., the role of an institution in producing articles in a scientific field) [45,49].

Science mapping is an essential procedure in the construction, analysis, and visualization of bibliometric networks [46]. It is considered a helpful approach "to clearly understand the concepts of science, making them more lively visible and concrete" [50] (p. 19). There are many software programs used for analyzing and visualizing bibliometric networks [51], each having advantages in one or several specific functions. CiteSpace, CiteNetExplorer, VosViewer, Publish or Perish, Pajek, and 
Gephi are considered to be "among the most important or most popular ones" [46]. Most of these software programs are open source or free for academic and non-profit use.

The bibliometric analysis of ESD has been less covered by scientific publications, particularly after 2014-2015, when the SDGs were introduced. Moreover, they do not look at ESD globally, but choose either a research field (e.g., tourism [52] or ocean exploration [53]), a journal (e.g., Journal of Cleaner Production [7] or Sustainability [10]), or just a topic (e.g., higher education [54]). Sometimes, they are limited to only one database (Web of Science or Scopus), but they do not study in-depth co-citation, for example, or they do not do mapping science [3].

Therefore, previous bibliometric studies provide the foundation for understanding the ways bibliometrics might be applied to the evaluation of scientific output from the ESD domain. On the other hand, Reunamo and Pipere claimed that the small number of existing studies "can be partly explained by the complex and constantly evolving nature of the ESD domain" [2] (p. 111).

A first substantial bibliometric analysis of ESD was carried out by Wright and Pullen in 2007 [1]. They engaged in a statistical description of the literature, analyzing the whole period between 1990 and 2005, but focusing exclusively on English language articles included in the ERIC database. What they found was that in the given period, the number of articles increased, but not significantly. The same held true for the number of journals. Only the number of authors increased substantially. Wright and Pullen also showed that articles based on ESD were published both in traditional journals and in interdisciplinary ones, illustrating the "global nature of ESD publication activities". At the same time, they noticed that certain academics saw ESD only from a specific academic field, such as environmental or health, and basically referred to ESD with a different term such as "Environmental Education" (EE).

However, in the literature, there is a whole debate about what distinguishes ESD from EE, as Briggs, Trautmann, and Fournier [55] (p. 14) highlighted in a large study on EE publications focused on Latin America and the Caribbean countries, between 2000 and 2018: "EE and ESD are characterized either as overlapping concepts or as two distinct philosophies". Nomura expressed concern that "ESD can only take an anthropocentric approach unlike EE" [56] (p. 621), while Maurer and Bogner [57], who carried out an analysis of sustainability concepts on 464 university freshmen, showed a large discrepancy between EE and ESD.

This "tension or transition" between EE and ESD as depicted by Reid and Scott [58] can be considered a limitation of bibliometric analysis, and Wright and Pullen claimed that a content analysis of the articles would lead to a more "meaningful future contribution to understanding the literature" [1] (p. 84). Yet, before 2007, no study had reflected on the nature of publications in the field nor investigated the direction of ESD publications.

A decade later, Côrtes and Rodriguez [4] conducted a bibliometric study surveying papers included in the WoS and Scopus databases between 1993 and 2015. Their aim was to offer input by analyzing the literature on Education for Sustainability (EfS) in order to identify future opportunities for research and to show the maturity level of the field. They investigated 279 papers, authored by 157 scholars from 36 countries, and revealed that Australia occupied the first position if we looked at countries (having more than $30 \%$ of the publications), followed by the U.K. (with $15 \%$ ) and the USA (with 14\%). The same was true for journals. Nevertheless, Côrtes and Rodriguez found that these data showed a certain lack of publication specifically about education for sustainability. The majority of articles came from the social sciences, "which have the characteristic of interdisciplinarity of themes and approaches" [4] (p. 14). The authors concluded "that there is a possibility of specific publications or special editions about such themes to emerge" [4] (p. 14).

Consequently, in 2017, Cullen [5] looked at the way in which the growth of interest in sustainability in business, management, and organizational studies was reflected in scholarly works between 1994 and 2013. Cullen's study was the first of this kind, and its main findings revealed that the number of published and quoted papers on sustainability as a general topic in business and management studies increased exponentially and that there was a variety of educational approaches to this topic in the literature. 
Veiga Ávila and his colleagues [7] undertook a quantitative and qualitative analysis of 5924 articles included in WoS about sustainability topics and EfS during 2005-2014. They also analyzed 17 articles published in a special issue dedicated to ESD by the Journal of Cleaner Production (January 2014). Veiga Avila and his colleagues found that the most dynamic field was that of sciences; most articles were published in 2013, and among the most representative authors were Donald Huisingh and Mathias Barth. The authors admitted that the main limitation of their study was the narrow area of research generated by the chosen database. They pointed out that "future studies of this nature should cover a greater range of sources", for example "national and international academic events, scientific journals, and other significant scientific databases" [7] (p. 117).

Trindade et al. [8] analyzed "the characteristics of scientific publications on the subject of EfS linked to theories of experiential, transformative, liberating and social learning". They looked at Web of Science and Scopus between 2007 and 2016, as well as at the proceedings of the National Association of Postgraduate Programs in Administration events in Brazil. Their findings were that the theory of social learning was the most solid in the literature. The results of their study enriched our knowledge about how learning theories can contribute to achieving the objectives of EfS. However, their study was quantitative in nature, without focusing on issues related to the quality of publications.

In a very recent study, Hallinger and Chatpinyakoop [54] analyzed 1459 Scopus indexed documents related to Higher Education (HE) for sustainable development. They found that the rapid growth rate of the knowledge base was due to scholars located in more economically developed societies. However, their findings revealed the need for diversification and for a more sophisticated implementation of research design.

What the authors of this article have noticed is that a global view of the field of ESD is missing. Moreover, according to Rickinson [59], there is a need for review papers "to have much stronger connections to the field's tradition of methodological discourse and debate". Thus, to the best of our knowledge, this is the first study that covers the whole period of 1992-2018, since the ESD notion was introduced and up to the present.

\section{Methodology}

The main aim of this paper is to conduct a bibliometric analysis of ESD papers indexed by WoS between 1992 and 2018. To achieve this goal, we set the following research objectives:

1. Establishing a descriptive structure such as the volume, distribution (based on the research field) and dynamics of ESD publications between 1992 and 2018, as well as the authors with the most publications, the scientific disciplines with most published results, etc.

2. Determining the impact scientific publications have on generating new knowledge. For instance, classical citations, the main actors (authors, institutions, countries, etc.), the papers that have contributed the most to the progress of scientific knowledge, the most influential journals for publishing the findings of studies, etc.

3. Tracing collaboration patterns (e.g., the degree of collaboration among authors, countries, or institutions).

4. Identifying key research areas and emerging trends (e.g., the major research areas, the most active areas, critical transitions in the development of the field, domains that were not explored by previous research, etc.).

\subsection{Methods and Tools}

As we have seen, there are several advantages to implementing bibliometric analysis for the purposes of this study: it allows a better understanding of the structure of scientific data; it gives the opportunity to identify, analyze, and evaluate the literature on this topic; it provides valuable insights into the chronological development of this field of research (past, present, and future); it enables us to identify the authors, articles, journals, topics, and citations that have an impact on the scholarly 
community; it gives the opportunity to establish the degree of interaction between authors, scientific papers, and journals, to summarize large datasets, and to identify popular issues and research trends. Bibliometric analysis also allows the identification of a circuit of knowledge between two or more research domains and gives the possibility to recognize new types of scientific research, as well as important issues for examining the subject more in depth.

We used bibliometric analysis to explore the four research aspects from the following perspectives: (a) content analysis for documents, authors, journals, institutions, and countries; (b) citation and co-citation analyses in order to identify the most important publications, highly cited authors, and the leading journals, institutions, and countries; (c) co-authorship analysis for authors, countries, and institutions; and (d) co-occurrence analysis to single out the research hotspots and emerging trends.

We worked with VoSViewer and CiteSpace to analyze and visualize bibliometric networks. VosViewer was developed by Van Eck and Waltman at the Centre for Science and Technology Studies from Leiden University, Netherlands. Having a friendly user interface, VosViewer provides both the basic functionality needed for visualizing bibliometric networks and the advanced features for creating such networks [46].

CiteSpace was developed by Chaomei Chen at Drexel University, USA and is a more specialized tool that has the advantage of categorizing data into different time subperiods and the capacity of visualizing the networks utilizing various layouts. CiteSpace, a real "X-ray machine for the literature" as Chen describes it [47], allows users to explore the intellectual landscape of a knowledge domain, to see how it evolved over time, and to identify the research hotspots and frontier directions in a certain field or domain [60].

Both software are freely available online and effective in information visualization [46,47]. We used them to construct co-citation networks, co-authorship networks, co-occurrence networks, and for burst detection.

\subsection{Sources and Data Collection}

The accuracy of a bibliometric analysis depends, first and foremost, on the search results in databases. If the aim is to analyze scientific productivity in a research field, one needs to make sure that this area is well represented in the database where the bibliographic search is performed. In fact, when we decide upon a database for a bibliometric study, we have to take into consideration at least two aspects: the degree to which the sources from a database cover specialized literature published in a particular domain and data accuracy (e.g., inconsistencies, mismatches, incorrect spelling of authors' names, or lack of standardization regarding titles or journals' affiliation).

Therefore, in order to get high quality documents, influential in the field of ESD, we used the Web of Science Core Collection. It is one of the most important sources of scientific documentation worldwide for detailed bibliometric analysis. We considered WoS to be the most relevant database for covering research on ESD, since it receives a large number of submissions. WoS, which has been including publications since 1945 and has a citation database dating back to 1900, communicates about $90 \%$ of the truly valuable research. Liao et al. [35] showed that, compared to other databases, the two indexes (Science Citation Index Expanded and Social Science Citation Index) include more scientific and authoritative publications. At the moment, the WoS Core Collection comprises over 12,000 peer-reviewed journals, across 150 disciplines of natural sciences, social sciences, and arts and humanities.

In order to identify documents, we based our search on PRISMA guidelines [61] for conducting a systematic review of research (see Figure 1). The criteria are listed in Table 1.

We focused our search strategy on three concepts rather than on just one: sustainability education, education for sustainability, and education for sustainable development. Although they are often used interchangeably (for example, the work in [62] used the term "sustainability education" for all forms of education concerning land and environment), until now, no bibliometric analysis has analyzed them together. On the other hand, even if we were primarily interested in articles published in journals, 
we decided to include in our dataset other document types as well, such as books, book chapters, conference papers, and reviews.

As a result, on 21 February 2019, we extracted a total of 1813 papers, which were downloaded in a tab separator format.
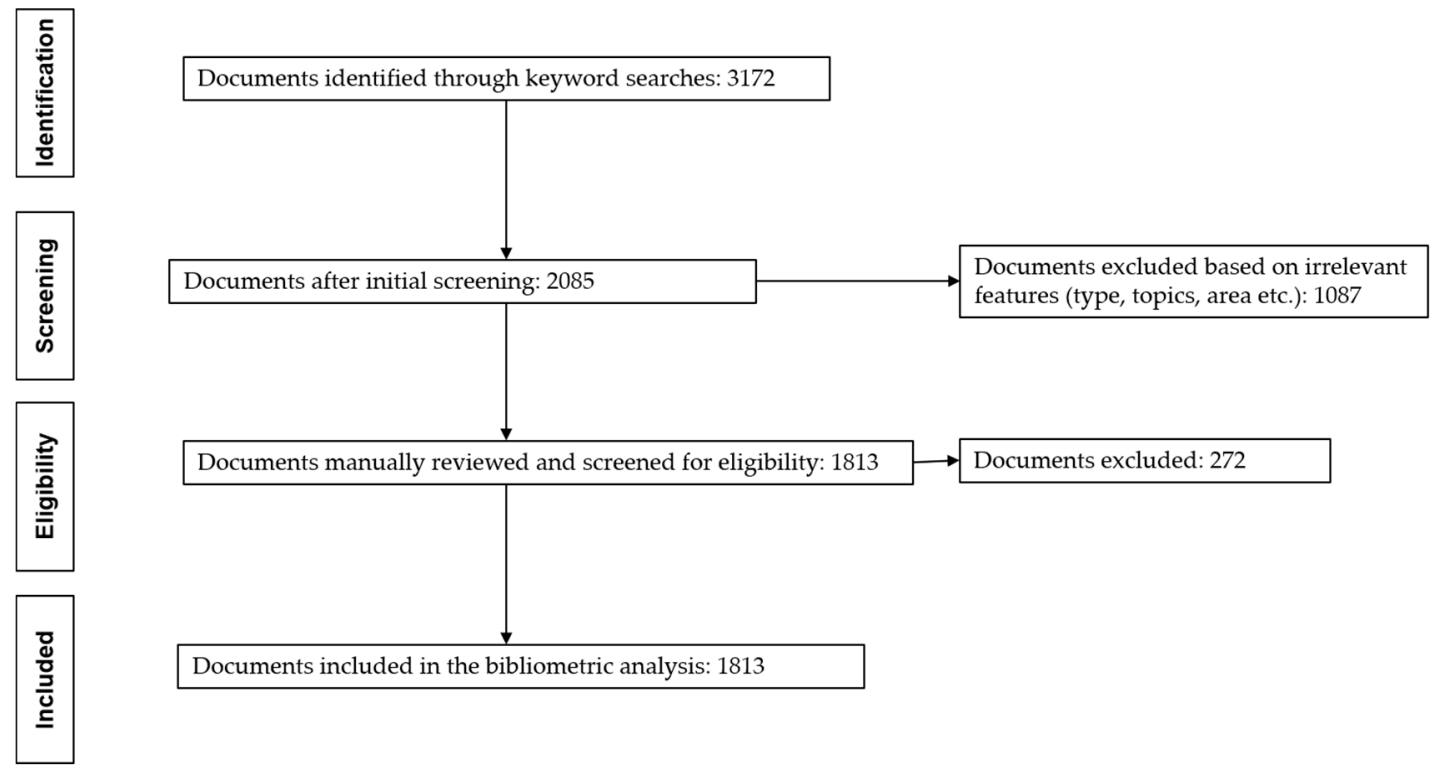

Figure 1. PRISMA guidelines describing the collection of documents from WOS.

Table 1. Search criteria.

\begin{tabular}{cc}
\hline Criteria & Details \\
\hline Database & Web of Science Core Collection \\
\hline Citation index & SCIE (Science Citation Index Expanded) and SSCI (Social Sciences Citation \\
Index)
\end{tabular}

\section{Data Analysis and Results}

In the following section, we present the results related to the research objectives.

\subsection{Content Analysis}

\subsubsection{Document Types}

Following the PRISMA guidelines, we identified 1813 papers. Fifteen types of documents were retrieved, the most frequent being the article (1347 papers), representing $74.29 \%$ of total publications. Other document types were proceedings papers $(18.09 \%)$, book chapters $(13.95 \%)$, editorial material $(3.80 \%)$, reviews $(2.20 \%)$, etc. The rest of the document types had insignificant shares (reprint, letter, etc.), except for meeting abstracts $(0.71 \%)$.

\subsubsection{Papers in Different Subfields/Categories}

In WoS, publications (journals, books, etc.) are sorted into more than 250 subject categories and 156 research areas. WoS includes only peer-reviewed literature of non-open access (traditional) or open access journals. 
There are more than 100 categories covering publications in journals or conferences. Therefore, we present only those that count 50 or more documents. The highest number (1079) was associated with the category education educational research (59.51\% of total publications). Next, at a considerable distance, we found green sustainable science technology with 570 papers $(31.43 \%)$, environmental studies with 413 publications ( $22.77 \%$ ), and environmental sciences with 315 documents $(17.37 \%)$. The following categories also had more than 50 recordings: engineering environmental, 142 (7.83\%), and education scientific disciplines, 101 (5.57\%). Engineering multidisciplinary, management, and regional urban planning each numbered 50 recordings $(2.75 \%)$.

Each WoS category was mapped to one research area. According to WoS, there are five broad categories of research areas: arts and humanities, life sciences and biomedicine, physical sciences, and social sciences and technology.

The top 10 research areas covered by documents from the set collection were: education educational research (social sciences), 1132; environmental sciences ecology (life sciences and biomedicine), 614; science technology other topics (technology), 575; engineering (technology), 229; business economics (social sciences), 117; social sciences other topics (social sciences), 65; public administration (social sciences), 50; geography (social sciences), 36; computer science (physical science), 33 and psychology (social sciences), 31. The data were in accordance with those obtained by Côrtes and Rodrigues [4], namely the vast majority of articles came from social sciences, and with those obtained by Veiga Ávila et al. [7], the most dynamic areas being those of sciences.

\subsubsection{The Annual Trends of ESD Related Publications}

Starting with the year 1996, a gradual rise could be noticed in the number of publications, and after 2014, there was considerable growth (see Figure 2).

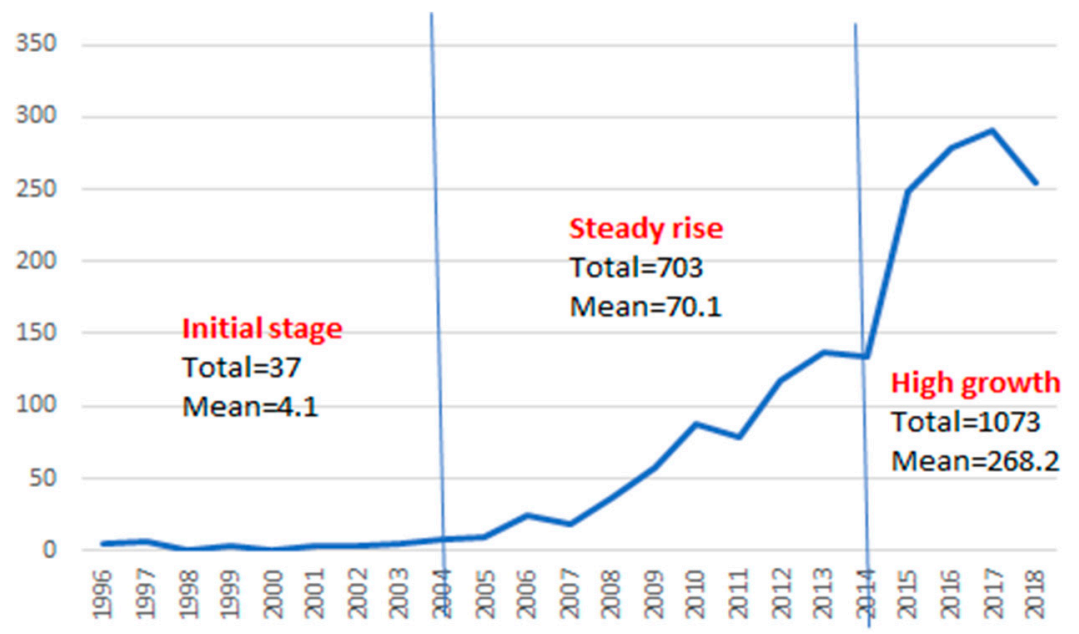

Figure 2. Number of WoS publications on ESD during the 1992-2018 period.

Although the time-span was set to start in 1992, the first document found in WoS dated from 1996. This could be due to the fact that only in 1996 was the concept of ESD formally developed at the fourth meeting of the United Nations Committee on SD [63]. As we can see in Figure 2, research on ESD is placed in a timeframe that can be divided into three stages: the initial stage (1992-2004), steady rise (2005-2014), and high growth (2015-present).

\subsubsection{Authorship}

We identified over 3000 authors, out of whom at least 10 published more than 10 articles. The top 10 included the following scholars: Thomas Ian, 20 (1.07\%), Barth Mathias, 17 (0.93\%), Leal Filho Walter, $16(0.88 \%)$, Shephard Kerry, 15 (0.82\%), Kopnina Helen, 14 (0.77\%), and Huisingh Donald, 13 
(0.71\%). Dlouha Jana, Rieckmann Marco, Van Poeck Katrien, and Wiek Arnim had 11 articles each (representing $0.60 \%$ of the total number of indexed articles).

The number of papers by the top 10 authors was 139 and only accounted for $7.67 \%$ of the 1813 papers.

\subsubsection{Countries/Regional Distributions}

As far as the countries or regions were concerned, 95 contributed to the 1813 papers analyzed by this study. The country where the author works was taken into consideration, which may be different from the country of birth or country of citizenship. From a geographical point of view, it can be noticed that the U.S. dominated the classification (15.88\%), followed by Australia (12.52\%), England (11.43\%), Germany $(8.10 \%)$, and Sweden (6.67\%). A significant number of articles (but still under 100) came from: Canada (4.68\%), Spain (3.86\%), The Netherlands (3.14\%), Japan (2.97\%), and China $(2.86 \%)$.

\subsubsection{The Distribution of Institutes on ESD}

More than 1000 organizations that contribute to the knowledge base of ESD related publications were identified. The great majority was universities or research institutes.

Royal Melbourne Institute of Technology (RMIT) University is the leading body in terms of the number of ESD related publications, with 42 papers accounting for $2.31 \%$ of all publications. It was closely followed by the University of Plymouth with 28 papers, representing $1.54 \%$, and Arizona State University with 26 papers $(1.43 \%)$. The next positions were held by Australian universities: Queensland University of Technology with 24 papers (1.32\%), James Cook University with 23 papers $(1.26 \%)$, and University of Tasmania with $20(1.1 \%)$. Leuphana University of Lüneburg and Manchester Metropolitan University each had 18 articles $(0.99 \%)$, while Griffith University and Rhodes University had entered the top 10 with a similar number of articles: $17(0.93 \%)$. The top 10 institutions generated $12.85 \%$ of the total articles.

\subsubsection{The Distribution of Published Journals on ESD Study}

Researchers published their findings in specialized academic journals that promote innovative ideas and give purpose and usefulness to their work. Like Rosas underlines, an analysis of journals is important in order to evaluate "the presence of a set of papers across scientific fields" [64] (p. 3). We looked at two bibliometric indicators applied to journals, namely impact factor and citation percentile.

For evaluating the prestige of scholarly journals, the best known and most used indicator is the Impact Factor (IF). It represents, for a given year and a journal, the ratio between the number of citations and the number of articles published in the two previous years. Auto-citations in the same journal are accepted in the IF calculation (according to the "presumption of innocence"). A high impact factor points to numerous citations of the articles in that journal, hence to the prestige of the articles. However, Bornmann and Marx [38] suggested that determining the quality of a journal can be done by using other bibliometric indicators. Thus, in order to establish the impact of a publication in comparison to other similar publications in the same subject category and year of publication, the citation percentile should be considered. It was defined by Waltman and Schreiber [65] as a percentile based bibliometric indicator that refers to the position of a paper (or a group of papers) with respect to other papers in a given discipline or research field, country, and/or a given time period, based on the number of citations they have received. After the publications are sorted by citation numbers, they are broken down into percentile ranks between zero and 100. The higher the percentile rank, the bigger the scientific impact of a journal. For example, if a journal is in the first quartile, that means the journal in question has a higher impact.

The 1813 research papers from our dataset were published in 732 traditional disciplinary and interdisciplinary journals. Table 2 presents the best journals for publication. 
Table 2. The top 10 best journals that include ESD-related publications, indexed in WoS, 1992-2018.

\begin{tabular}{|c|c|c|c|}
\hline Journal & IF (2018) & Quartile in WoS Category & Papers \\
\hline Environmental Education Research & 2.255 & $\begin{array}{l}\text { Education and Educational } \\
\quad \text { Research, Q1 } \\
\text { Environmental Studies, Q3 }\end{array}$ & 173 \\
\hline $\begin{array}{l}\text { International Journal of } \\
\text { Sustainability in Higher Education }\end{array}$ & 1.437 & $\begin{array}{c}\text { Education and Educational } \\
\text { Research, Q3 } \\
\text { Green and Sustainable Science and } \\
\text { Technology, Q4 }\end{array}$ & 144 \\
\hline Journal of Cleaner Production & 6.395 & $\begin{array}{l}\text { Engineering, Environmental, Q1 } \\
\text { Environmental Sciences, Q1 } \\
\text { Green and Sustainable Science and } \\
\text { Technology, Q1 }\end{array}$ & 120 \\
\hline Sustainability & 2.592 & $\begin{array}{c}\text { Environmental Sciences, Q2 } \\
\text { Environmental Studies, Q2 } \\
\text { Green and Sustainable Science and } \\
\text { Technology, Q2 }\end{array}$ & 94 \\
\hline $\begin{array}{c}\text { Australian Journal of } \\
\text { Environmental Education }\end{array}$ & - & - & 32 \\
\hline Journal of Environmental Education & 2.04 & $\begin{array}{l}\text { Education and Educational } \\
\quad \text { Research, Q1 } \\
\text { Environmental Studies, Q3 }\end{array}$ & 32 \\
\hline $\begin{array}{c}\text { Journal of Geography in Higher } \\
\text { Education }\end{array}$ & 1.533 & $\begin{array}{c}\text { Education and Educational } \\
\text { Research, Q2 } \\
\text { Geography, Q3 }\end{array}$ & 20 \\
\hline Sustainability Science & 4.669 & $\begin{array}{c}\text { Environmental Sciences, Q1 } \\
\text { Green and Sustainable Science and } \\
\text { Technology, Q2 }\end{array}$ & 16 \\
\hline $\begin{array}{l}\text { Journal of Professional Issues in } \\
\text { Engineering Education and Practice }\end{array}$ & 1.372 & $\begin{array}{c}\text { Education, Scientific Disciplines, Q3 } \\
\text { Engineering, Multidisciplinary, Q3 }\end{array}$ & 15 \\
\hline Research in Science Education & 1.382 & $\begin{array}{c}\text { Education and Educational } \\
\text { Research, Q3 }\end{array}$ & 14 \\
\hline
\end{tabular}

The core journals focus on subject areas such as environmental and sustainability education, sustainability in higher education, sustainability and sustainable development, engineering education, and science education.

The Journal of Cleaner Production stands out due to its high IF and because for three domains, it is placed in Q1. An interesting case is that of the Australian Journal of Environmental Education, which does not yet have an IF (it is listed in the Emerging Sources Citation Index), but has a greater number of publications than other journals with a high IF.

Before moving to the second research aspect, we can summarize the results of the content analysis section as follows: The most frequent document type was the article (74.29\% of total publications), and most documents were published in social sciences (78.92\%). Publications on ESD can be divided into three time frames: initial stage, steady rise, and high growth. The high growth occurred during the Decade of Education for Sustainable Development. Thomas Ian was the author with the biggest number of publications (20). His affiliation was with RMIT, which was also the most active institute when it came to publications (42 papers, representing 2.31\%). The country that generated the most publications was the USA (15.88\%), and the most popular journal was Environment Education Research with 173 papers ( $9.54 \%$ out of the total publications). 


\subsection{Citation and Co-Citation Analysis}

\subsubsection{Citation and H-Index Analysis}

According to Eck and Waltman [46], citation analysis is an efficient way to study communication within the academic community, the structure of a science from an interdisciplinary point of view, as well as the mechanisms of creating new knowledge. Citation is also extremely important for determining the significance of a scientific article. Tahamtan and Bornmann [66] discovered a strong correlation between citation frequency and a paper's intrinsic scientific value, the number of citations being the main factor that reflects a paper's quality. This correlation has been statistically proven on samples of world-famous researchers, including Nobel laureates [67].

Regarding direct citations corresponding to our dataset, we used the WoS indicators. Thus, the 1813 publications were cited 11.891 times, 8070 of them being bibliographic references without counting auto-citations. The number of papers citing these articles was 5688, out of which 4748 were articles without bibliographic auto-citations.

The Hirsch index (or h-index) is a tool used to evaluate researchers' and academic institutions' scientific performance and impact. A researcher has an $h$-index if $h$ publications out of the total number of his/her publications have at least an $\mathrm{h}$ number of citations each and his/her other publications have been cited not more than $\mathrm{h}$ times each. The Hirsch index calculates simultaneously the quality and impact of research over time. The h-index can also be calculated in order to establish the overall value of publications by researchers in an institution, university, or country when looking at a particular scientific field.

For our dataset, the average citations per item was 6.56, while the h-index was 46.

From Figure 3, one can notice that, after 2010, there was a steady increase in the number of citations, which confirmed both the researchers' growing interest and the evolution of the field.

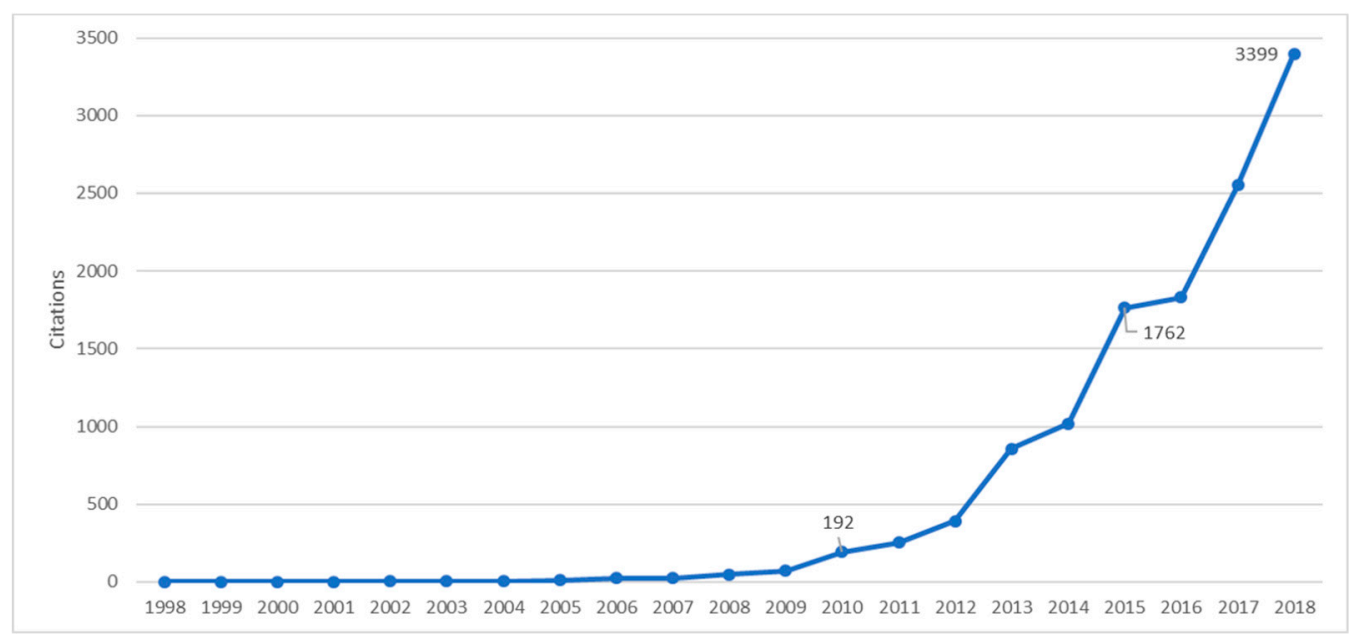

Figure 3. Citation dynamics from 1992 up to the present (WoS).

According to Roemer and Borchardt [42], one of the best bibliometrics indicators to compare the impact of different scientists over time is the h-index. Citations are like fingerprints of scientific achievements, and they witness the evolution of ideas. Table 3 introduces the authors who have brought important contributions to the advancement of ESD. 
Table 3. Top 10 most cited ESD authors, 1992-2018.

\begin{tabular}{cccccccccc}
\hline Author & \multicolumn{3}{c}{ WoS } & \multicolumn{3}{c}{ Scopus } & \multicolumn{2}{c}{ Google Scholar } \\
\hline & h & Documents & Citations & h & Documents & Citations & h & Documents Citations \\
\hline Wiek, A & 31 & 11 & 680 & 35 & 100 & 5304 & 44 & 146 & 10,163 \\
Huisingh, D & 35 & 10 & 632 & 37 & 112 & 4099 & & NA * \\
Lozano, R & 29 & 8 & 624 & 30 & 64 & 3795 & 37 & 138 & 7388 \\
Redman, CL & 35 & 3 & 546 & 25 & 156 & 2464 & 49 & 197 & 20,355 \\
Lambrechts, W & 9 & 7 & 435 & 9 & 16 & 709 & 12 & 100 & 1531 \\
Lozano, FJ & 10 & 4 & 411 & 37 & 250 & 4530 & 13 & 36 & 1869 \\
Lukman, R & 11 & 4 & 385 & 11 & 16 & 1101 & & NA * & 1397 \\
Withycombe, L & 2 & 1 & 376 & 7 & 14 & 622 & 10 & 17 & 1392 \\
Rieckmann, M & 9 & 11 & 370 & 8 & 19 & 650 & 18 & 154 & 2322 \\
Wals, AEJ & 23 & 8 & 352 & 24 & 94 & 2078 & 46 & 510 & 9101 \\
\hline
\end{tabular}

$\mathrm{h}=$ Hirsch index; ${ }^{*} \mathrm{NA}=$ Not Available.

Until now, there has been no single citation analysis tool that collects all publications and their cited references. Therefore, in order to find out the impact top 10 authors have had, we also included in Table 3 the h-index for Google Scholar (GS) and Scopus. Since GS does not provide the total number of documents, special software (e.g., Publish or Perish) is required to count an author's references. Interestingly, although Thomas Ian had the most published papers (20), he was not the most cited.

Bibliometrics is not designed to evaluate research performance directly, so this type of analysis should be accompanied by qualitative analysis as well.

Table 4 identifies the highly cited papers as reported by WoS. For each paper from the top 10, we can single out the title, the journal, the authors, the year of publication, the research area, keywords, the total number of citations, and three variables for the Number of Authors (AN), number of organizations (IN) (higher education institutions or research institution), and the country of origin (CN). Four papers in the top 10 were published in the Journal of Cleaner Production, and $12.31 \%$ of the total number of citations belonged to the first most influential ten papers.

The top 10 countries and their respective number of citations were: USA (2947), England (1971), Australia (1423), The Netherlands (1397), Germany (1156), Sweden (997), Belgium (744), Mexico (556), Spain (513), and Canada (468). USA, England, and Australia had the most cited publications and the most significant published scientific papers.

The institutions with the best performances in terms of citations received by papers authored by people affiliated with these institutions were: Arizona State University (761), University of Plymouth (404); RMIT University (364); Leuphana University Lüneburg (254); Griffith University (158); Queensland University of Technology (147); Manchester Metropolitan University (125); James Cook University (89); University of Tasmania (68); and Rhodes University (27). These ten institutions can also be found in the top 10 featuring the institutions with the most scientific publications. Arizona State University had the largest proportion of received citations (761). Many of these articles were written as part of research projects funded by universities. For example, from WoS, we learned that James Cook University financed 54 papers (23 of which were in the top 10), whereas Arizona State University funded 27 (26 in Top 10).

According to the analysis provided by VosViewer, the top 10 most cited journals were (the number of citations is included in brackets): Environmental Education Research (2919), Journal of Cleaner Production (2060), International Journal of Sustainability in Higher Education (1232), Sustainability (1222), Journal of Environmental Education (671), Sustainability Science (432), Journal of Education for Sustainable Development (402), International Journal of Science Education (344), Journal of Business Ethics (328), and Sustainability-Basel (328). As we saw earlier, Table 2 features the journals attracting most researchers for publication. If we also look at the number of citations, we can observe a correspondence between the two classifications only for the first five journals, with slight changes in order. Positions 6-10 were occupied by journals that cannot be found in the top 10 most attractive for publication, but which accurately reflect the diverse research interests from the field of ESD. 
Table 4. The top ranked papers by citation.

\begin{tabular}{|c|c|c|c|c|c|}
\hline Title & Authors & Journal & Year & Citations & $\mathrm{AN} / \mathrm{IN} / \mathrm{CN}$ \\
\hline $\begin{array}{l}\text { Key competencies in sustainability: a reference } \\
\text { framework for academic program development }\end{array}$ & $\begin{array}{l}\text { Wiek, A.; Withycombe, L.; } \\
\text { Redman, CL }\end{array}$ & Sustainability Science & 2011 & 377 & $3 / 1 / 2001$ \\
\hline $\begin{array}{c}\text { Declarations for sustainability in higher education: } \\
\text { becoming better leaders, through addressing the } \\
\text { university system }\end{array}$ & Lozano, R et al. & Journal of Cleaner Production & 2013 & 219 & $5 / 5 / 2005$ \\
\hline $\begin{array}{l}\text { Ethics, CSR, and sustainability education in the } \\
\text { Financial times top } 50 \text { global business schools: Baseline } \\
\text { data and future research directions }\end{array}$ & Christensen, LJ; et al. & Journal of Business Ethics & 2007 & 193 & $5 / 3 / 2001$ \\
\hline $\begin{array}{l}\text { Globalization and environmental education: looking } \\
\text { beyond sustainable development }\end{array}$ & Jickling, B. Wals, AEJ & Journal of Curriculum Studies & 2008 & 168 & $2 / 1 / 2001$ \\
\hline $\begin{array}{l}\text { Real-world learning opportunities in sustainability: } \\
\text { from classroom into the real world }\end{array}$ & $\begin{array}{c}\text { Brundiers, K.; Wiek, A. Redman, } \\
\text { CL }\end{array}$ & $\begin{array}{l}\text { International Journal of } \\
\text { Sustainability in HE }\end{array}$ & 2010 & 136 & $3 / 1 / 2001$ \\
\hline $\begin{array}{c}\text { Future-oriented higher education: Which key } \\
\text { competencies should be fostered through university } \\
\text { teaching and learning? }\end{array}$ & Rieckmann, M. & Futures & 2012 & 125 & $1 / 1 / 2001$ \\
\hline $\begin{array}{l}\text { Higher education for sustainability by means of } \\
\text { transdisciplinary case studies: an innovative approach } \\
\text { for solving complex, real-world problems }\end{array}$ & Steiner, G.; Posch, A. & Journal of Cleaner Production & 2006 & 123 & $2 / 1 / 2001$ \\
\hline $\begin{array}{c}\text { A review of commitment and implementation of } \\
\text { sustainable development in higher education: results } \\
\text { from a worldwide survey }\end{array}$ & Lozano, R. et al. & Journal of Cleaner Production & 2015 & 105 & $9 / 8 / 2007$ \\
\hline $\begin{array}{l}\text { The action competence approach and the 'new' } \\
\text { discourses of education for sustainable development, } \\
\text { competence and quality criteria }\end{array}$ & Mogensen, F.; Schnack, K. & $\begin{array}{l}\text { Environmental Education } \\
\text { Research }\end{array}$ & 2010 & 96 & $2 / 2 / 2001$ \\
\hline $\begin{array}{c}\text { Academic staff development as a catalyst for curriculum } \\
\text { change towards education for sustainable development: } \\
\text { an output perspective }\end{array}$ & Barth, M.; Rieckmann, M. & Journal of Cleaner Production & 2012 & 90 & $2 / 2 / 2002$ \\
\hline
\end{tabular}




\subsubsection{Co-Citation Analysis}

Bibliometric analysis focuses not only on bibliographic statistics from the literature and on citations, but also makes use of citation networks based on the links between documents that cite and documents that are cited.

When two items (such as documents, journals, and authors) have at least one item in common they both cite, we are talking about bibliographic coupling, and when both are being cited in the same item, then we are talking about co-citation, even if they do not directly cite one another [46].

The more often they are cited together by more items, the stronger their relationship [35]. In the case of citation relations, bibliographic coupling is the opposite of co-citation. As we shall see in what follows, there is a distinction between direct citation relations, bibliographic coupling relations, and co-citation relations [46], each of them having its own advantages or disadvantages relative to the others. On the other hand, for social sciences and humanities, Glänzel [68] suggested a combined use of bibliographic coupling and co-citation.

In both visualizations made by VosViewer (Figure 4a,b), each circle represents a researcher. If the circle is larger, researchers have more publications that meet the analysis criteria. The closer the researchers are, the more strongly they are linked to each other.

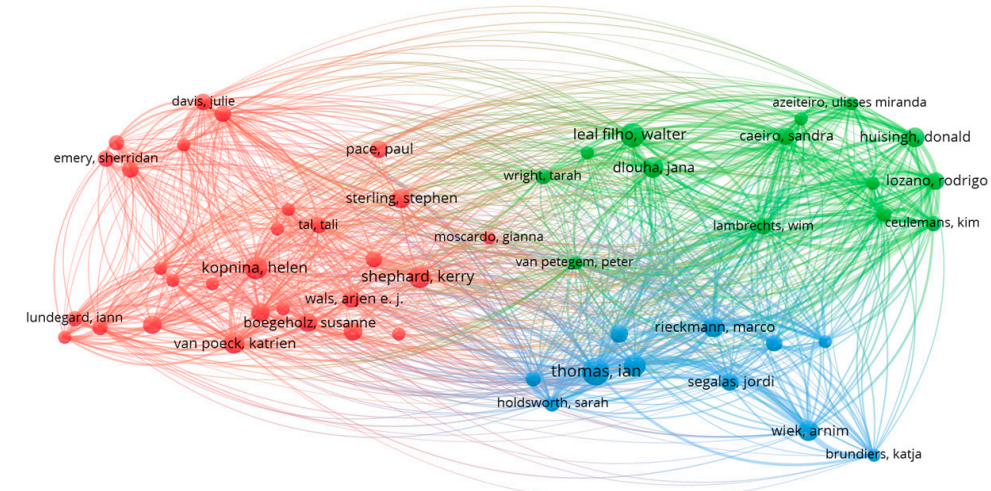

fis vosviewer

(a)

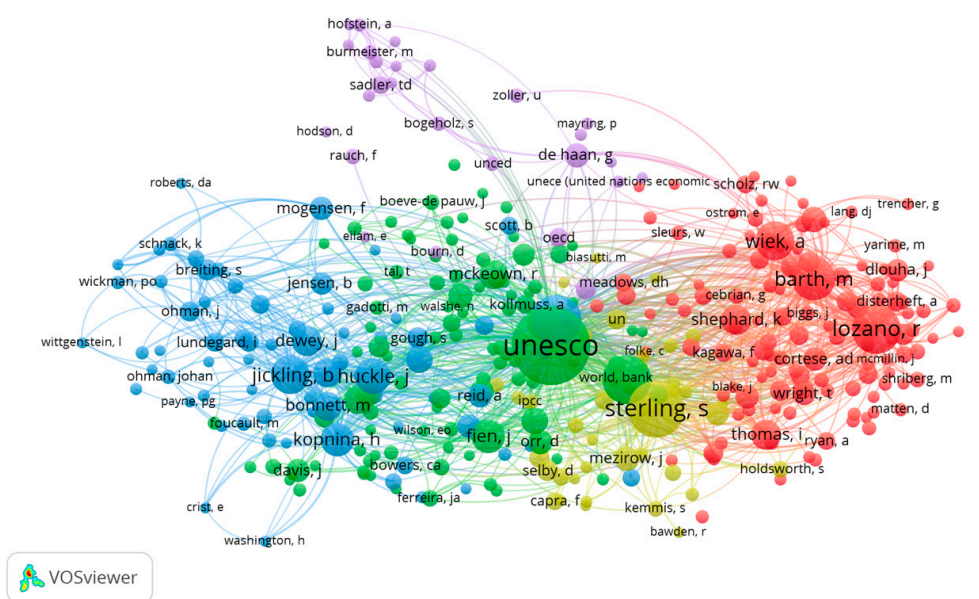

(b)

Figure 4. (a) Bibliographic coupling network of researchers (cluster view: of the 29,235 authors, 54 meet the threshold). (b) Top 10 co-cited ESD authors, 1992-2018 (of the 29,235 authors, 362 meet the threshold, minimum number of citations for an author 20). 
In the bibliographic couple analysis, the top scholars were: Wiek Arnim (680), Huisingh Donald (632), Lozano Rodrigo (624), Lambrechts Wim (435), Rieckmann Marco (370), Wals Arjen (352), Barth Matthias (335), Ceulemans Kim (275), Katja Brundiers (256), and Kopnina Helen (228).

In the visualization from Figure $4 \mathrm{~b}$, we can spot the top 10 co-cited authors: UNESCO (1015), Sterling Stephen (534), Wals Arjen (413), Lozano Rodrigo (402), Tilbury Daniella (398), Barth Matthias (310), Jickling Robert (247), Wiek Arnim (245), Huckle John (210), and Fien John (187).

Only Wals, Lozano, and Wiek appeared in both analyses.

The next step was to identify the most influential documents (see Table 5) by doing a co-citation analysis with VosViewer on 48,143 valid references (149 met the threshold with a minimum number of 20 citations of a cited reference).

Table 5. The top 10 most co-cited publications (1992-2018).

\begin{tabular}{|c|c|}
\hline Cited Reference & Citations \\
\hline $\begin{array}{l}\text { Wiek A, Withycombe L, Redman CL. Key competencies in sustainability: a reference framework } \\
\text { for academic program development. Sustainability Science. } 2011 \text { 1;6(2):203-218. }\end{array}$ & 127 \\
\hline $\begin{array}{l}\text { UNESCO. UN Decade of Education for Sustainable Development. Links between the global } \\
\text { initiatives in education. } 2005\end{array}$ & 90 \\
\hline $\begin{array}{l}\text { Cortese AD. The critical role of higher education in creating a sustainable future. Planning for } \\
\text { Higher Education. } 2003 \text { Mar 15;31(3):15-22. }\end{array}$ & 82 \\
\hline $\begin{array}{l}\text { Lozano R. Incorporation and institutionalization of SD into universities: breaking through barriers } \\
\text { to change. Journal of Cleaner Production. } 2006 \text { 1;14(9-11):787-96. }\end{array}$ & 77 \\
\hline $\begin{array}{l}\text { Jickling B, Wals AE. Globalization and environmental education: Looking beyond sustainable } \\
\text { development. Journal of Curriculum Studies. } 2008 \text { 1;40(1):1-21. }\end{array}$ & 72 \\
\hline $\begin{array}{l}\text { Barth M, Godemann J, Rieckmann M, Stoltenberg U. Developing key competencies for sustainable } \\
\text { development in higher education. International Journal of Sustainability in Higher Education. } \\
2007 ; 8(4): 416-430 .\end{array}$ & 71 \\
\hline $\begin{array}{l}\text { Lozano R, Lukman R, Lozano FJ, Huisingh D, Lambrechts W. Declarations for sustainability in } \\
\text { higher education: becoming better leaders, through addressing the university system. Journal of } \\
\text { Cleaner Production. } 20131 ; 48: 10-9 .\end{array}$ & 70 \\
\hline $\begin{array}{l}\text { Sipos Y, Battisti B, Grimm K. Achieving transformative sustainability learning: engaging head, } \\
\text { hands and heart. International Journal of Sustainability in Higher Education. 2008; 9(1):68-86. }\end{array}$ & 69 \\
\hline $\begin{array}{l}\text { Wals A, Jickling B. "Sustainability" in higher education: From doublethink and newspeak to } \\
\text { critical thinking and meaningful learning. International Journal of Sustainability in Higher } \\
\text { Education. 2002; 3: 221-232. }\end{array}$ & 62 \\
\hline $\begin{array}{c}\text { World Commission on Environment and Development (WCED). Our Common Future. Oxford } \\
\text { University Press. } 1987 .\end{array}$ & 59 \\
\hline
\end{tabular}

When we looked at citation dynamics, we also had to take bursts into consideration. Xiao et al. [69] explained that citation burst is an alternative method by means of which we can obtain "evidence that the publication has attracted an extraordinary degree of attention from its scientific community". This usually occurs within a few years after the publication of a paper [40].

The visualization from Figure 5 shows which references had the strongest citation bursts and during which periods of time the strongest bursts took place (marked with red).

UNESCO's [70] publication ranked first, since it was a landmark, a fundamental reference for ESD. The aforementioned organization established this paradigm and promoted it at the global level by means of relevant and consistent educational programs.

Finally, we looked at the journal co-citation. The visualization of co-citation networks of journals is presented in Figure 6, where each circle represents a journal. Circle dimensions are proportional to the number of papers citing the corresponding journal. If journals are closer, it means they tend to be more strongly related, based on co-citations. 


\begin{tabular}{|c|c|c|c|c|c|}
\hline References & Year & Strength & Begin & End & $1992-2018$ \\
\hline UNESCO, 2005, UN DEC ED SUST DEV 2, V0, P0 & 2005 & 8.6178 & 2009 & 2013 & \\
\hline SCOTT W, 2003, SUSTAINABLE DEV LEAR, V0, P0 & 2003 & 7.382 & 2008 & 2011 & \\
\hline LUNDEGARD I, 2007, ENVIRON EDUC RES, V13, P1, DOI & 2007 & 4.9722 & 2008 & 2012 & \\
\hline DAWE G, 2005, SUSTAINABLE DEV HIGH, V0, P0 & 2005 & 4.736 & 2008 & 2011 & \\
\hline MCKEOWN R, 2003, ENVIRON EDUC RES, V9, P117, DOI & 2003 & 4.6646 & 2005 & 2011 & \\
\hline STERLING S, 2001, SUSTAINABLE ED REVIS, V0, P0 & 2001 & 4.5468 & 2006 & 2009 & \\
\hline TILBURY D, 2005, NATL REV ENV ED ITS, V0, P0 & 2005 & 4.2792 & 2008 & 2013 & \\
\hline KOMIYAMA H, 2006, SUSTAIN SCI, V1, P1, DOI & 2006 & 3.7955 & 2009 & 2011 & \\
\hline CORTESE AD, 2003, PLANNING HIGHER ED, V31, P15 & 2003 & 3.7955 & 2009 & 2011 & \\
\hline SUMMERS M, 2005, ENVIRON EDUC RES, V11, P623, DOI & 2005 & 3.3535 & 2009 & 2013 & \\
\hline
\end{tabular}

Figure 5. Top 10 references with the strongest citation bursts.

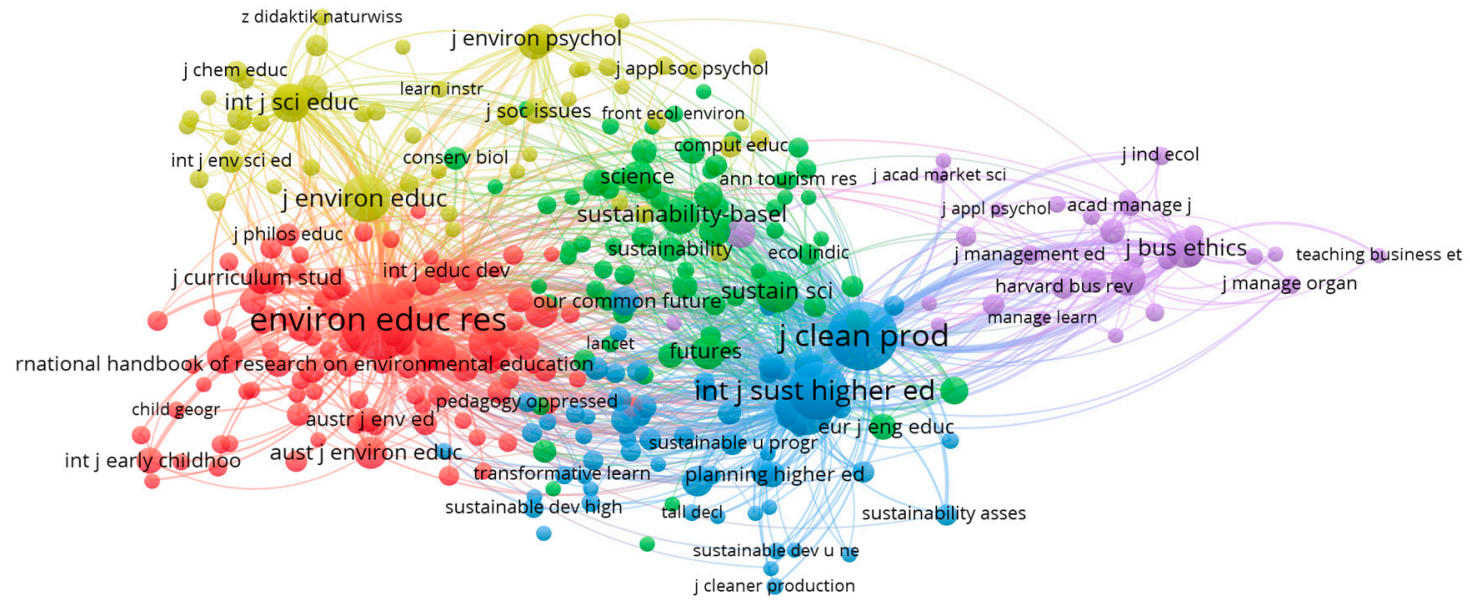

禹 Vosviewer

Figure 6. Co-citation networks of journals (of the 27,001 sources, 328 meet the threshold/journals quoted less than 20 times were not included).

VosViewer identified five clusters. In each of them, we could distinguish a core journal around which the others gravitated. Thus, the red cluster included Education Environmental Research (2919) and the Journal of Education for Sustainable Development (402) and can be labeled as the advanced research on ESD cluster. The blue cluster, focused more on sustainability education research, brought together the Journal of Cleaner Production (2060) and the Journal of Sustainability in Higher Education (1232). The green cluster was oriented towards environment education related publications, and it included International Journal of Sustainability (1222), Sustainability-Basel (315), and Sustainability Science (432). The purple cluster (focused on economic issues) contained the Journal of Business Ethics (328), while the yellow one combined social sciences and science and included the International Journal of Science Education (344) and The Journal of Environmental Education (671).

To sum up this section, ore main findings were: the data collection was cited 11,891 times, with an average citation per item of 6.56 (h-index $=46$ ); the most cited author was Wiek Arnim (h-index of 31 in WoS, 35 in Scopus, and 44 in Google Scholar), having 680 citations in WoS; the article "Key competencies in sustainability: a reference framework for academic program development" (main author Wiek) was considered the most influential, receiving 377 citations; the countries with the most citations were USA, England, and Australia; the most cited institution was Arizona State University (USA), whereas the most influential journal was Environmental Education Research with 2919 citations, followed by the Journal of Cleaner Production with 2060 citations. 


\subsubsection{Co-Authorship and Collaboration Patterns}

Modern scientific research is collaborative and requires the efforts of researchers from various fields of study, from different institutions, and from international backgrounds. Scholarly cooperation is reflected at the level of scientific communication by articles published in collaboration in a variety of journals. In order to understand this collaboration, with the help of VosViewer, we carried out an analysis of co-authorship patterns on authors, countries, and institutions.

Based on the dataset from 1992-2018, there were 3562 authors contributing to 1813 papers. The map presented in Figure 7a shows the network of co-authorship links between authors of publications or those that have co-authored with them, while in Figure $7 \mathrm{~b}$, we present for the most cited author, Wiek, his position and role in the collaborative network.

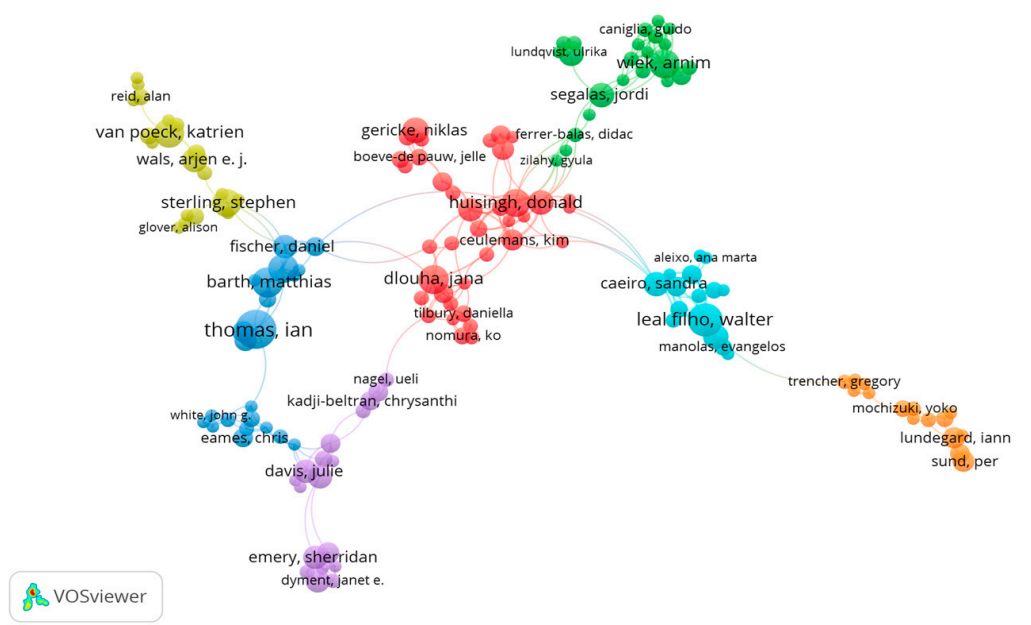

(a)

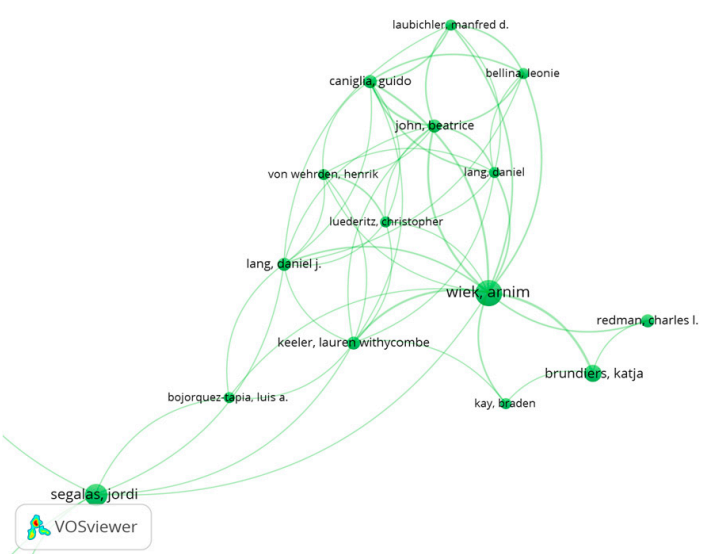

(b)

Figure 7. (a) Map of authors with collaborative links (out of 3562 authors, 367 meet the thresholds, minimum number of documents/authors $=2$, minimum number of citations/authors = 5); $(\mathbf{b})$ Wiek's co-authorship network.

In Figure 7a,b, the "bubbles" represent authors. The size of the nodes represents the number of papers, whereas the lines show a collaborative relationship. Two authors united by a line have co-authored one or more publications.

The map from Figure 7a also illustrates the different research communities in the field of ESD and the connections between them. Authors that have co-authored also tend to be located close to each other on the map. Seven collaborative groups were found. Colors indicate clusters of authors that are relatively strongly connected by co-authorship links. As one can see, there are some cooperation 
patterns between the topmost productive and cited authors (e.g., Thomas's papers are associated with other top-ranked authors like Barth).

Let us look at the highly cited author Arnim Wiek (Figure 7b). Between 2006 and 2018, Wiek had 82 entries in WoS and 4192 citations (3872 if we leave out auto-citations). However, only one of these was as a single author. The other 81 were written in groups of researchers, which varied in number from two to 47. Wiek was the lead author in 21 papers. The paper with the most authors was a review article, published in 2018 in a journal having IF $>5$. The authors came from 42 universities from all continents. For now (September 2019), it only has 24 citations. Although we cannot firmly state that the more authors, the more citations, our results were similar to those of Faze et al. [71]. Besides, research is a "slow business", and the average length of time it takes to receive a bigger number of citations is usually 3-4 years after the publication. Wiek has written most papers together with Lang Daniel (12), but his most cited ones were those authored with Redman (their articles appeared twice in the top 10).

Collaborative patterns were analyzed for countries, as well. Figure 8 shows which countries were most influential in the field (the big nodes), as well as the degree of communication between countries (the links between nodes represent the cooperative relationships).

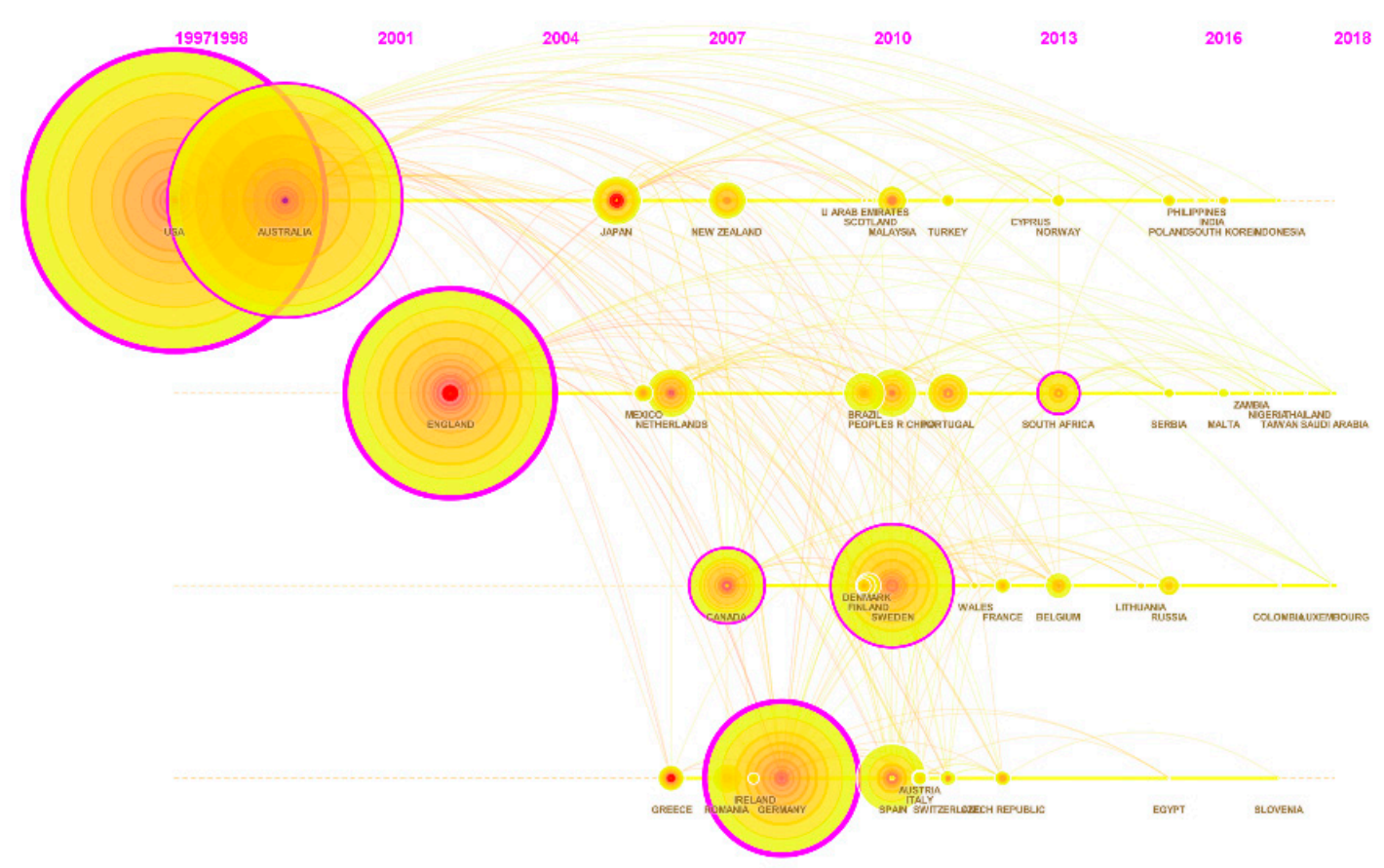

Figure 8. The dynamics of international collaboration between countries (1992-2018). The country co-authorship network: CiteSpace Timeline view.

We can see in Figure 8 that several countries tended to work together for a major cluster and that each cluster usually had one or two more core countries. Three countries can be singled out for most publications and citations: USA, England, and Australia.

By looking at the clusters placed further from the core countries, such as the one that includes Romania, Germany, or Ireland, we can remark that the "geographical advantage is not the primary factor that influences the cooperative relationships" [35] and that ESD is a field of interest for researchers all over the world.

As far as collaboration between institutions is concerned, from Figure 9, we can see that regional cooperation predominated (the blue cluster groups together universities from the Scandinavian peninsula, and the red one brings together Australian universities). Significant as well is the cooperation among diverse European institutions (University of Belgrade, University of Manchester, University of Aveiro, etc.). Nevertheless, global international collaboration seems to be missing. 


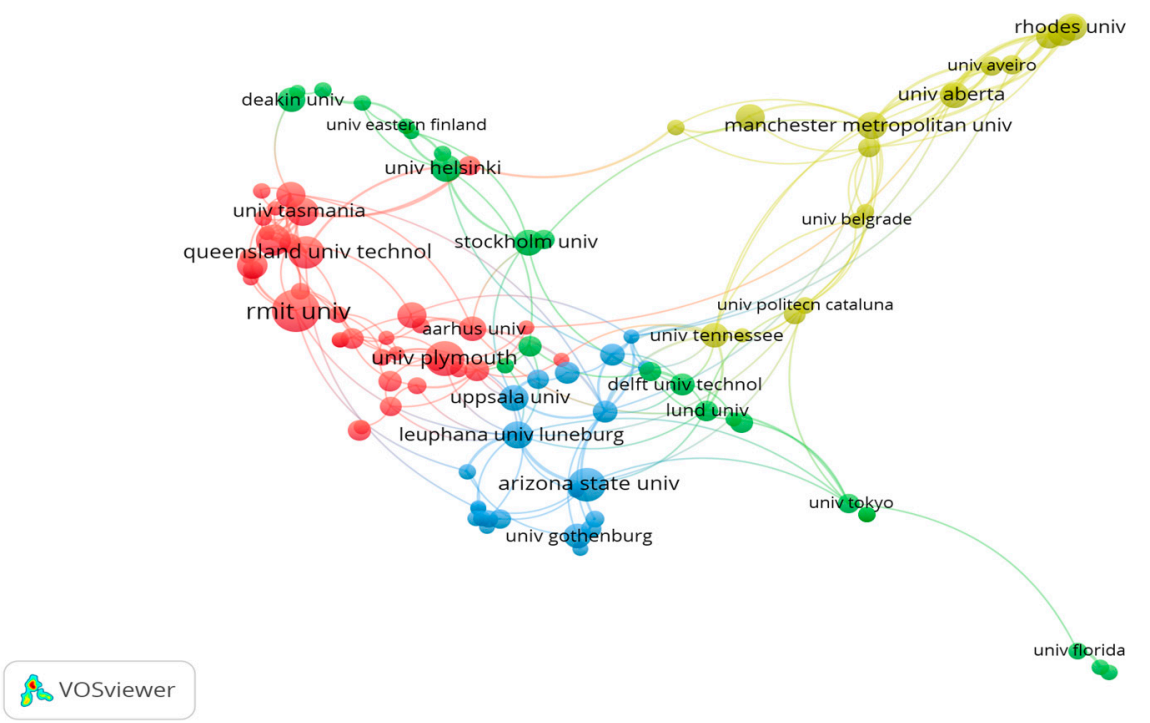

Figure 9. The institution co-authorship, 1992-2018.

Regarding collaborative research aspects, our study's results can be summed up as follows: there were some collaborative patterns between the highly cited, most productive authors; countries tended to work together for a core-country, and regional cooperation among institutions predominated.

\subsubsection{Keywords Analysis}

For identifying research hotspots, those central categories around which all others gravitated, and concepts or emerging trends, we undertook a keywords analysis with CiteSpace. There were several ways through which we could obtain keywords: from the title, from the abstract of a publication, or straight from the keyword list supplied by the author of a publication.

In the visualization featured in Figure 10, each term is represented by a cross. The size of a cross is directly proportional to the number of publications that contain the term either in the title or in the abstract. Terms that co-occur often tend to be located close to each other in the visualization.

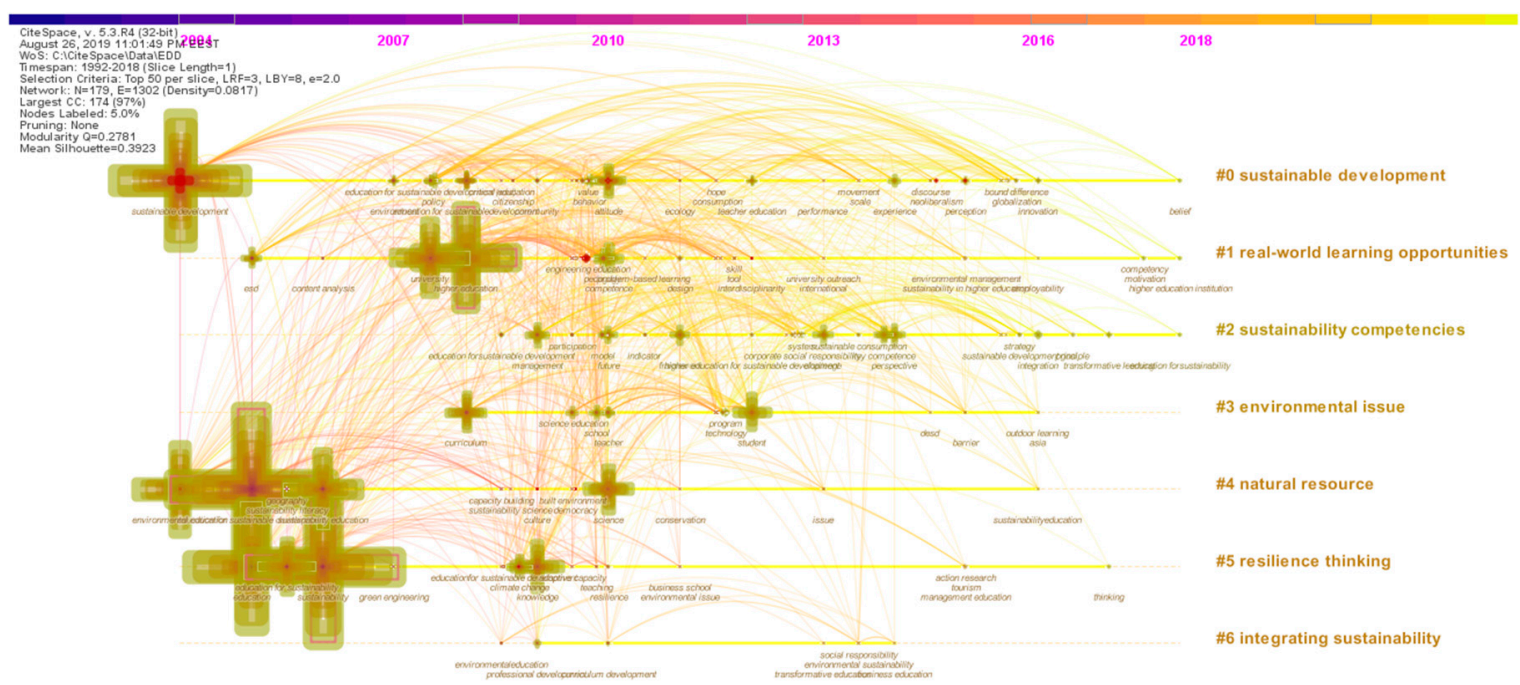

Figure 10. Clusters as a whole, capturing active areas of research and emerging trends, 1992-2018 (keywords co-occurrence network map, CiteSpace Timeline view).

Furthermore, we made a citation burst in order to identify which topic received the most attention in the literature (the strongest citation bursts and the periods of time during which the strongest bursts took place, see Figure 11). 


\begin{tabular}{lcrll}
\multicolumn{1}{c}{ Keywords } & \multicolumn{1}{c}{ Year } & Strength Begin & End \\
environmental education & 1992 & 5.0907 & $\mathbf{2 0 0 4}$ & 2005 \\
sustainability & 1992 & 2.7149 & $\mathbf{2 0 0 6}$ & 2007 \\
education & 1992 & 1.6736 & $\mathbf{2 0 0 7}$ & 2008 \\
sustainable development & 1992 & 11.1814 & $\mathbf{2 0 0 7}$ & 2011 \\
policy & 1992 & 2.3409 & $\mathbf{2 0 0 8}$ & 2009 \\
climate change & 1992 & 4.0847 & $\mathbf{2 0 0 9}$ & 2010 \\
culture & 1992 & 6.4651 & $\mathbf{2 0 0 9}$ & 2011 \\
educationfor sustainable development & 1992 & 5.5338 & $\mathbf{2 0 0 9}$ & 2011 \\
teaching & 1992 & 4.312 & $\mathbf{2 0 1 0}$ & 2013 \\
learning & 1992 & 3.6159 & $\mathbf{2 0 1 0}$ & 2013
\end{tabular}

Figure 11. Top 10 keywords with the strongest citation bursts, 1992-2018.

To conclude the keywords analysis, we can say that ESD was no longer just a matter related to teaching and learning. Besides being "complex and manifold in their interrelation" [72], the key topics were all relevant themes for ESD and crucial to SD processes at the local and/or global level.

\section{Discussions}

As we have shown in the previous section (Data Analysis and Results), we retrieved some interesting results. In what follows, we will present our findings associated with the four research objectives.

\subsection{Content Analysis}

The analysis of document types indicated that journal articles constituted the biggest segment, approximately $75 \%$ of the total number of documents. In other words, out of all the document types recorded in WoS, the article was the main means of communicating scientific information, followed by books, proceedings papers, and reviews (less important). Other types of documents were also registered, but their proportion was much smaller.

In order to retrieve these documents, we used three terms in the selection criterion, namely SE, EfS, and ESD. There is no difference in meaning, so we treated them as synonyms. However, Australia adopted Education for Sustainability (EfS) rather than the UN terminology of ESD, and much of the research that was reported at the national level as ESD was also reported as Environmental Education (EE) or Education for Sustainability (EfS), interchangeably [73]. So far, we have not found bibliometric approaches for all three terms in the literature.

Then, we decided to consider conferences' proceedings as document types. Even though the quality might vary with respect to the reviewing process of registered papers and/or scientific committees and some journals accept for publication even presentations, our rationale was that some research results are presented only during conferences and do not get published. What is more, some presentations do get published, but much later and in a changed version (e.g., in a conference, one publishes only a stage in the research process).

Although an analysis of published papers can also be done starting from the language in which they were written, all 1813 documents from our dataset were in English, which reinforces what Hallinger and Chatpinyakoop found, namely that "the coverage of documents in other languages remains quite uneven" [54].

The number of publications is just one of the possible quantitative features of an author's contribution to the information process worldwide, and it is an incomplete one. We have seen that scientific publications in the field of ESD are of various types. Regarding their value and contribution to the development of the field, we decided to also analyze the categories and domains in which they were included in WoS. We found that research related to ESD entailed great efforts on the part of professionals from various scientific areas and disciplines. At the same time, this research links several 
diverse research disciplines and areas, due to the increasing complexity of current social and economic processes, as well as to the need for dealing with growing environmental risks. Thus, the articles were divided into different categories like "education and educational research", "environmental sciences and ecology", or "geography, science and technology", which confirms the idea that fertile scientific contributions can be found in very diverse sources (journals, books, conferences, etc.). Publications related to ESD are not restricted to specialized journals.

It should also be mentioned that, according to the characteristics of a journal or a conference, a paper can be recorded in more than one research field. There were 3113 research documents, which means that there were many interdisciplinary papers. Hence, ESD basically brings contributions to all scientific fields (education, environment/earth science, ecology, economy, public administration, social sciences, computer science, etc.), which opens up new paths of integrative research. If we were to look at the computer science research area, we could find 33 interdisciplinary papers, distributed on research segments as follows: engineering (9), educational research (6), business economics and telecommunications (two papers each), and one paper for each of the research areas: agriculture, information science library, public administration, social sciences, and women's studies. The six articles at the intersection of computer science and educational research were put out in recent years in the proceedings of IEEE conferences on e-learning, computing education, technology for education, or advanced learning technologies. The topics tackled in these publications are diverse: the use of Information and Communication Technologies (ICT) as a pedagogical tool in order to raise awareness on key sustainability issues [74], the use of ICT in teaching and learning on ESD [32], or the inclusion of innovative experiences on ICT in the curricula in order to develop content about sustainability issues [75].

These works on digitalization as an imperative for sustainable development, on the ways in which ICT can support ESD, and on ICT applications in educational systems acknowledge the challenges brought by new technologies and applications (the Internet, in particular) to ESD. As Makrakis rightly remarked: "ICTs can thus be a context for ESD as well as ESD can be a context for ICT" [76].

Furthermore, interdisciplinary domains are ever more relevant to scientific research in ESD, and scientific events can channel knowledge in this field. In truth, ESD is too complex to be fully covered by accessing a single research domain. In this respect, our results are consistent with those of Veiga Ávila et al. [7].

Based on the annual trends of ESD related publications analysis, we divided the evolution of research into three stages:

(a) From 1992 to 2004, the initial stage, with only 37 records in total. The first article in the database was issued in 1996, compared to 1998, found by Hallinger and Chatpinyakoop [54]. Until 2005, there was a slight increase in the number of publications. For roughly the same period (1990-2005), Wright and Pullen [1] reported that the number of articles on ESD increased from 64 in 1990 to 162 in 2004, but this growth was nonlinear.

(b) Between 2005 and 2014, we are in a steady rise stage, the total records being 703 . Figure 2 illustrates that, starting with 2005, the number of publications tended towards a dynamic growth and peaked in 2014, when 134 articles were published. According to [1] (p. 80), "while it is beyond the scope of bibliometry to investigate the causes of the observed peaks and increase, it is conceivable that they correspond with various international efforts to promote ESD." Indeed, this stage coincides with the UN Decade on Education for Sustainable Development. The articles written in this period were, in general, research papers concerned with integrating sustainable development principles and practices in all aspects of education. The topics mirrored the aim of the decade to encourage change in knowledge, values, and attitudes, conducive to a more sustainable and fair society for all. Starting with this period as well and continuing into the following years, ESD sparked the interest of both researchers and mass-media. A series of research and awareness campaigns was initiated, regarding the need for EfS and SD. 
(c) From 2015 to the present, we are talking about the stage of high growth. There were 1073 papers published in this period, with a peak (291) in 2017. Basically, since the formal concept of ESD emerged internationally, there has been a steady rise in the number of publications, which proves that ESD is an active area of research. According to [1], a simple explanation for this growth may be the fact that in 2015, during the UN summit organized in New York, Agenda 2030 for sustainable development was drafted and adopted by all member states, together with its 17 SDGs. As a result, papers published after 2015 focused more on the role of education for the achievement of sustainable development, especially from the perspective of SDG4: Quality Education for All.

For the future, we can expect the production of literature on ESD to grow constantly, as we are witnesses to a significant development of research.

The rankings showed the presence of valuable researchers, usually scholars with a longstanding interest in ESD, who can become key-players in developing research strategies in this field. RMIT associate professor Thomas Ian was the author with the most "solo publications". In his research, he focused mainly on the implementation of environmental education and sustainability education in Australian universities and the development of graduate capabilities for sustainability.

At the same time, each author from the top 10 developed and conducted research on innovative teaching and learning approaches in sustainability programs. For example, Matthias Barth's (the second place) emphasis was on competence development, innovative learning settings, and curriculum change, while Arnim Wiek's (the $10^{\text {th }}$ most prolific author) major research interests were in urban development, resource governance, climate change, and public health.

On the other hand, every country had a different level of development and a different cultural background. This can cause considerable differences in their understanding of ESD [63]. Classifications based on countries with the largest number of publications and citations were dominated by OECD member states. A possible explanation could be that in developing countries, research connected to ESD received less support from the state. In contrast, research emerging from OECD member states proliferated at a great speed, probably also because in these countries, there are more universities and research institutions (than in non-OECD ones) that require a constant publication policy in the field of SD (UN, 2019). Wright and Pullen [1] claimed this statement cannot be proven by a bibliometric analysis, but it is an aspect worthy of investigation in future studies.

It is important to stress that, since 2015, no country (not even the most developed ones in the world like the USA, Australia, or Japan) has achieved or is on track to achieve all SDGs [77]. Among the top 10 countries with the most publications, Sweden is the closest to achieve the SDGs with a score of 85, as reported in the SDG Index and Dashboards 2018. In order to improve, major transformations are needed that require partnerships involving multiple stakeholders: business, government, academia, and civic society.

However, China is a notable exception in these rankings. Usually, China's economic growth is described as "unstable, unbalanced, uncoordinated and ultimately unsustainable" [78]. As an important world player and leader in the technological field, China demonstrated it is "one of the world's fastest growing economies" and can no longer be considered a developing country. Although SD has been a fundamental national policy in China since 1992, back when the Chinese government started to implement Agenda 21 [79], "little analysis has taken place regarding the progress of ESD in China" [80], "no research has been done to summarize education development associated with sustainability in China" [81], and "less knowledge is available to understand how existing SE programs were designed" [17]. There is "an urgent need to conduct extensive research on sustainability" (Yang and Jiang, 2019), and it should be noted that the rate of Chinese scientific articles on ESD growth has been high since 2015, the year in which its "leadership confirmed its intention to advance international agendas such as the Sustainable Development Goals and the fight against climate change" [82].

It should also be highlighted that 10 out of the 52 contributions selected as "resident" in China were, in fact, written in collaboration with authors from the European research space (Brighton University, University of Lisbon). This stands as proof for the fact that common EU-China engagements and 
interests regarding global sustainable development and Agenda 2030 offer opportunities for a tighter cooperation. Therefore, on the one hand, China is/can be a crucial partner in promoting SD and solving global environmental issues, and on the other hand, China is working alongside the EU in view of finding common solutions to global threats and towards building a better future for human society, "to keep pace with the world and its challenges" [78].

There is no doubt that the impact of research from the USA, Australia, and England is the most significant, since it accounts for $39.87 \%$ of the total articles. Although ESD is an issue of global concern, Nomura [56] suggests it should be "contextualized more in harmony within the global south." It is equally true that OECD member states have shown more commitment to this field compared to other countries, like those in the Asia-Pacific region or sub-Saharan Africa [23]. In places such as Indonesia or Bangladesh, there are serious issues connected to the evolution of sustainable lives, economies, and societies, and "the application of innovative curriculum, content, progressive pedagogy, sustainability-oriented teaching materials, practice standards, monitoring and auditing mechanisms for ESD teachings are very much required" [56,83].

According to our data, the most active institution was RMIT, a university committed to incorporating sustainability principles and practices into learning and teaching, research, and operational activities. An impressive number of 42 articles were published in the past decade (2008-2018) by RMIT affiliated authors. In fact, Thomas Ian, the author with the most published papers in the field of ESD, works at RMIT. Four other Australian universities can be found in the top 10, a clear indication that institutions from this continent are determined to incorporate sustainability in the curriculum of various courses and even to develop fresh study programs (such as Master's of Global development from James Cook University). Some Australian universities are running Massive Open Online Courses (MOOCs), thus supporting the idea that open education (open educational resources and their offspring, MOOCs) is a valuable and significant factor in meeting the UN and UNESCO's goals, especially in achieving SDG4 [27]. To give just one example, "The Science and Practices of Sustainable Development" is a MOOC run by edX, created by The University of Queensland, part of a MicroMasters program in global development.

Zutshi, Creed, and Connely [9] argued that sustainability initiatives should occupy a strategic place in higher education institutions, while Alba-Hidalgo, del Alamo, and Gutierrez-Perez [84] recognized the mature experiences associated with environmental sustainability in connection with the main pillars of a university's activity: teaching, research, facilities, and services. In this sense, universities began collaborating and adopting external standards. Among these standards, we came across "The Talloires Declaration", the first official declaration made by university representatives that highlights the need for SD in higher education and outlines ways and areas of implementation. The mission of universities is to boost SD, with a special focus on teaching, research, and attracting colleagues from institutions throughout the world by means of publications, research, and assessment. By January 2019, 505 universities from about 200 countries had adhered to the Talloires Declaration, including all five Australian ones from the top 10 most productive institutions. To conclude, the Australian context shows how universities can serve as an important example for other institutions in the process of implementing sustainability initiatives in the academic sphere.

From our dataset, 660 articles (36.4\%) featured in the prestigious top 10 highly productive and visible specialized journals (e.g., Journal of Cleaner Production, IF $=6.395$, found in Quartile 1 for all three categories: engineering, environmental, environmental sciences, and green and sustainable science and technology). One hundred seventy three of these papers (9.542\% out of the total number) appeared between 2008 and 2018 in Environmental Education Research, whose mission is "to advance research-based and scholarly understandings of environmental and sustainability education". One hundred twenty one were articles, most of which were published in 2018, when there were 12 issues/per year compared to other years when we had 6-10 issues.

Thus, ESD seems to be well received by the academic community, particularly since a series of articles was included in international journals with a high impact factor. If we looked at the 
quartiles in which these journals were placed, we could notice that researchers tended to pursue a rather moderate publication strategy (in Q2 and Q3, there were 11 publications). There were also contributions following an aggressive publication strategy (in Q1, six publications), and very few adopted a conservative strategy (in Q4, only one). All in all, the great majority of research in this field met high quality standards.

A better choice for article submissions might be Open Access (OA) journals. Open access is considered the best way to improve knowledge flow. In Europe, for example, one of the objectives launched by the Horizon 2020 program stipulates 100\% availability of open access scientific production. The number of open access publications (in our dataset) was 345 . The 10 leading open access journals are (the number of papers is in brackets): Sustainability (96), Procedia Social And Behavioral Sciences (28), Environmental Education Research (19), Education Sciences (12), International Journal of Sustainability in Higher Education (10), Policy Practice A Development Education Review (9), Journal of Cleaner Production (8), Sustainability Science (7), European Journal of Sustainable Development (5), and the Third World Conference on Educational Sciences 2011 (4).

Interestingly, two conference proceedings were among the top 10: Procedia Social and Behavioral Sciences and Third World Conference on Educational Sciences 2011, which confirms our belief that including conferences in the search widens the citation spectrum for a domain. These findings concur with those of [7].

Open access related to our dataset also revealed receptiveness and transparency in research. The annual quota of open access papers varied in the WoS category between 35 and 38\% for education educational research, environmental studies, and green sustainable technology and environmental sciences and $6-14 \%$ for engineering multidisciplinary, energy fuels, education scientific disciplines, economics, and engineering environmental and social sciences disciplinary. This is an excellent indicator in the context of promoting open access policies for digital scientific content at the European and international level.

\subsection{Citation and Co-Citation Analysis}

By taking citations into account as indicators of usage and visibility, we were able to assess the structure of the essential part of fundamental literature on ESD, regarding important documents, authors, and journals. At the same time, citation context analysis gave us useful perspectives on the performance of certain scholars and research groups, regarding the impact citations have on researchers' work.

The most cited author was that of Wiek Arnim; he was also the lead author of the most cited paper. The 11 documents included in WoS brought him 680 citations.

From Table 3, we can see that the overlap in citations between WoS, Scopus, and Google Scholar was rather small. However, the number of works indexed in WoS was significantly smaller than in Scopus (GS does not even show the total number of papers; therefore, we used Publish or Perish to scan these authors). Obviously, this situation led to significant differences in the number of citations and to different h-indexes. Harzing [85] demonstrated that, in general, GS produced twice as many citations as WoS and almost as many as Scopus. In our case, however, GS provided on average 7-8 times more citations than WoS, and Scopus almost $4-5$ times as many.

Browsing the most cited papers provided a very quick understanding of ESD mainstream related research and its major trends. Although their content was varied, the articles were drawn toward two major themes. The first, identifying key competences in sustainability, featured papers that explored: the action competence approach [86], how real-world learning opportunities can contribute to the acquisition of key competencies in sustainability [87], which are the most relevant competencies for SD to be fostered through university teaching and learning, and what are the critical gaps in their conceptualization $[88,89]$.

On the other hand, the second, implementation of ESD in higher education, tackled aspects such as: how to deal with the complex problem of SD in higher education through a transdisciplinary 
real-world case study approach [90]; how to include and cover the topics of ethics, corporate social responsibility, and sustainability in higher education institutions [91]; the role of academic institutions as sustainability leaders and change drivers, and what efforts are made to convert environmental education into ESD [92]; academic staff development as a catalyst for curriculum change [93]; how university leaders' intentions can help to improve the effectiveness of ESD [94], or what is needed to shift towards a sustainable university [95], etc.

These articles appeared between 2006 and 2015, more or less in the UN Decade of ESD. The content and themes discussed showed that the authors embraced the main goal of DESD to integrate SD into all facets of education and learning in order to create a more sustainable future. On the other hand, citations could sometimes be perceived as more important than the article's content.

In terms of relative impact, American research was outstanding with $13.45 \%$ of all citations referencing papers from the USA. Except for Belgium and Mexico, all the other countries were found in the top of most publications. Belgium and Mexico had a small number of published works, 31 and 25, respectively, but have a big number of citations. Hence, these two countries had scientific performances in the area of quality ESD research. It also had to be mentioned that there was an international interest in Mexico, which, unfortunately, was not one of the pioneer countries in terms of sustainability. However, researchers seemed attentive to the developments in this country, judging by the large number of citations.

Interestingly, if Japan and China were in the top 10 when it came to publications, in Positions 9 and 10 respectively, they occupied Positions 12 (with 385 citations) and 18 (with 217 citations) in the citation count. China has had a remarkable evolution, however. Chinese articles are increasingly cited internationally, and this might be due to the fact that it is the first country to set up a national citation index. At the end of 2007, a partnership agreement was sealed with Thomson Reuters (now Clarivate Analytics), stipulating that the Chinese Science Citation Database would be hosted by the ISI Web of Knowledge platform. Currently, it is available on the Web of Science and can be browsed in English.

Authors from China focused on research themes that highlight advances in academic efforts for implementing sustainability in higher education: the students' perspective on HE for SD, sustainable universities (green campus, green universities), introducing ESD in university curricula, student environmental awareness, etc. This complies with China's commitment to its National Plan for Medium and Long-term Education Reform and Development (2010-2020). Since 2010, ESD has been a national strategy of education development in China [63].

The top 10 institutions added up to $20.15 \%$ citations from the total of articles in WoS, which confirmed their importance for ESD research. However, Australian institutions predominated, possibly because UNESCO's Decade of Education for Sustainable Development triggered the "agenda setting and concrete actions around sustainability and EfS" [96], making sustainability one of the three cross-curriculum priorities incorporated into the Australian Curriculum, into all learning areas and at all levels. Naturally, much research had to be done for ESD to be embedded efficiently and relevantly. The content of articles by Australian authors took up various topics, which were important for the Australian curriculum, such as teachers' perceptions of sustainability, the curriculum and/or teaching practices, blending learning techniques that promote EfS, understanding the institutional change of education for sustainability in universities, the EfS policy processes from development to implementation, etc.

The quality and prestige of a journal is built on the quality of published papers. From the journals' citation analysis, we saw that the most cited one was "Environmental Education Research", with around 3000 citations. P.O. Seglen [97] argued that citation quotas of scientific papers determine the impact factor of a journal, and not the other way around. The more a journal and the articles included in it are quoted, the bigger its impact factor.

Besides descriptive statistical methods, we used two bibliometric ones, namely bibliographic coupling and co-citation analysis. Bibliographic coupling plays an important role in bibliometric mapping and in finding information. The power of co-citation between two items is given by the 
frequency with which they show up together in reference lists. Bibliographic coupling is the number of references shared between two items that are citing [98]. The power of co-citation and bibliographic coupling thus expresses the similarity between two journals, two authors, or two documents, as it is reflected by the authors' reference system.

The three clusters in the visualization from Figure 4 of the bibliographic couple networks included researchers who most often shared a common research vision. In the red cluster, we could spot key scholars like Wals Arjen, Ceulemans Kim, or Kopnina, Helen. These researchers shared interests surrounding globalization and environmental education: natural resource management, developing competencies and pedagogical approaches for sustainability, environmental values, and ethical approaches, etc. The green cluster pointed to top scholars, such as Huisingh Donald, Lozano Rodrigo, Lambrechts Wim, or Barth Matthias. Their common research was within the large field of sustainability in higher education: implementation of sustainable development in universities, teaching sustainability issues in higher education institutions, collaboration with communities for ESD, developing key competencies for higher education, etc. In the blue cluster, one could see top-ranked scholars such as Wiek Arnim, Rieckmann Marco, and Katja Brundiers, who all had as research goals projects linked with research and innovations through academic curricula.

Co-citation is important for bibliometric analyses also because it offers a broader perspective on researchers' influence than direct citation analysis.

In Figure $4 b$, we can notice a center-periphery pattern, with an essential segment being formed around the most cited authors (e.g., Sterling or Lozano). UNESCO [70] featured as a top co-cited author, which is not surprising due to the fact that UNESCO is the main proponent of ESD research and practice all around the world, providing mass materials research on ESD since 1992 [63].

Only three scholars (Wals, Lozano, and Wiek) were identified through direct citation, bibliographic coupling, and co-citation. One would expect the situation to be the opposite: just 2-3 scholars not present, for example, in the top 10 most cited authors (direct citation). Therefore, direct citation, bibliographic coupling, and co-citation analysis did not overlap. However, if we looked at these classifications, we had a general image; hence, the mutual reinforcing of these three methods illustrated the capacity of co-citation analysis to identify influential authors.

The most influential paper was authored by Wiek, Withycombe, and Redman [88] as it was ranked first in the top 10 cited and co-cited publications. The main aim of the article was to identify both relevant literature and critical gaps in the conceptualization of key competencies in sustainability. We accessed WoS and found out that the number of citations for this paper went up from 377 to 453 from the beginning of the year and up to the time of drafting this article (September 2019). Citation dynamics can be explained by the fact that, according to its authors, insights from this study can be considered groundwork for institutional advancements in designing and revising academic programs, but also for teaching and learning evaluations, or hiring and training faculty and staff. On the other hand, the lead author, Wiek, is associate professor at Arizona State University, which backs up the assertion that each researcher is the "architect" of scientific visibility of the institution to which they belong. In Table 5, there were two papers (UNESCO and WCED) that did not meet publication standards of scientific articles, but they are fundamental to ESD. This strengthens Hallinger and Chatpinyakoop's belief that analyzing co-citation is a method to detect those documents that bring major contributions to the literature in a field besides the database being used [54].

To visualize the journals that are important for the main literature, we carried out a co-citation analysis on journals. The biggest impact on the field came from Education Environmental Research and the Journal of Cleaner Production. The data associated with Figure 6 indicated an asymmetrical distribution of journal citations: 13 journals were cited 20 times and 26 more than 100 times.

Last but not least, the spread of journal citations and co-citations helped evaluate the influence of different disciplines on a domain. A large part of references corresponded to a wide range of other disciplines, such as economy (Journal of Business Ethics, $\mathrm{IF}=3,796$ ) or sciences (International Journal of Science Education, IF $=1.255$ ). Themes often featured in these journals are linked to ethical approaches 
of SD, corporate SD, sustainability science education, teachers' perspectives and competences on EE, etc.

\subsection{Co-Authorship Analysis}

The next step was to perform a co-authorship analysis to measure the scientific impact of researchers and to assess the collaboration trends between authors, countries, and institutions. Usually, the co-authorship analysis looks for answers to basic questions such as: "Who collaborates with whom and how?", "Does collaboration truly influence the impact?", "Can past collaborations be assessed?", "What happens with collaborations between industries and universities?" etc.

To delineate the scientific impact (quality) of a researcher, in addition to the number of co-authored publications, the work in [36] also analyzed "the extent to which co-authorship becomes international in the sense of collaboration". With one exception, Rieckmann [89], we see in Table 4 that all the articles were the result of collaboration. In general, authors came from different institutions, only three papers being the product of international cooperation. Although the top 10 was dominated by institutional collaboration, this was mainly achieved locally or regionally, which calls for extending cooperation internationally.

In addition to Ellegaard and Walin's suggestions [36], Glänzel [41] advised using co-authorship analysis in conjunction with the h-index analysis. The main collaboration trends were between visible researchers (measured by a high Hirsch score and a high number of citations) with other visible researchers (e.g., Wiek and Brundiers), but also with less visible academics (e.g., Wiek and Foley).

Finally, by looking at institutions (Figure 9), it became clear that ESD has evolved into one of the most fertile domains of international scientific cooperation. Multi- and inter-disciplinary networks of researchers from different countries function with direct or indirect support from public or private research organizations and centers. However, by using a quantitative analysis method, we can only speculate on why researchers collaborate, write in co-authorship, or engage in knowledge sharing.

\subsection{Co-Occurrence Analysis}

In order to identify the themes that are most commonly discussed among academia and the topics that are representative for research in the period 1992-2018, we looked at the keywords' synthesis made by CiteSpace (Figure 11).

The highest frequency term was clearly ESD (516). If we left out the search terms (ESD (516), SE (163), and EfS (138)) together with S (300) and SD (288), the most frequent topics studied in the literature were: education (247), higher education (232), environmental education (219), university (146), knowledge (105), curriculum (98), science (96), attitudes (74), students (73), management (57), competences (51), framework (49), pedagogy (44), environment (39), challenges (39), future (38), teachers (38), policy (37), behavior (36), and engineering education (36).

According to the analysis of the results from CiteSpace, it was seen that the software divided the keywords into seven clusters. The keywords from the clusters were the key topical foci, those keywords that reflected the focus of the authors and their papers. As depicted in Figure 10, the prominent research directions (throughout the period of 1992-2018) were gathered in the following seven major clusters: sustainable development, real-world learning opportunities, sustainability competencies, environmental issues, natural resources, resilience thinking, and integrating sustainability. In each cluster, the term ESD was connected to almost all the other words/topics. At the same time, all the words had at least one link to each other, which delineated the main research areas in which studies were made and issues related to ESD could be found (i.e., those areas in which research questions have been posed, but no answer has been given yet).

"Sustainable development" is an important cluster throughout the entire period, since it addresses general research topics such as understanding ESD definitions, concepts, curriculum or theory, exploring the global research agendas and practices on ESD, mainstreaming ESD into educational policy, etc. The "real-world opportunities" cluster covers transdisciplinary studies that explored 
the role of higher education in solving real-world sustainability problems, analyzed how real-world learning opportunities contribute to the acquisition of key competencies in sustainability, etc. The "sustainability competences" cluster drew attention to building educators' and trainers' capacities, stimulating learning and promoting the core competencies in ESD, articulating them in the educational programs, and so on.

The "environmental issues" cluster encompassed research on critical perspectives of environmental education, such as the essential role of eco-pedagogy in citizenship and empirical insights on integrating critical environmental issues into the curriculum (e.g., global climate change, loss of biodiversity, pollution, waste disposal, and many others). "Natural resources" was a cluster that summarized research on integration of natural resources into the curriculum, education about sustainable use and management of natural resources, learning about conservation of natural resources, ecological footprints, major risks and consequences, use or abuse in preserving natural resources, etc.

The "resilience thinking" cluster included more action-oriented research, with scholars focused on exploring the critical characteristics of applying resilience thinking to $\mathrm{SD}$, building resilience in socio-ecological systems, achieving sustainable and resilient societies, teaching resilience, etc. Finally, the "integrating sustainability" cluster referred to the development of ESD through the integration of $\mathrm{SD}$ into education systems and the integration of education as a means to achieve SD; the relevance of ESD in relation to the achievement of all the SDGs, but also to empowering youth and local communities as critical drivers for SD; how to scale ESD or transformative education for sustainability and responsible citizenship.

Besides the progress and issues of ESD research, from the co-occurrence analysis, we can also identify emerging concepts within themes. Some of the trends that caught researchers' attention in recent years were: teaching students about the problems of moving into a circular economy [99]; disruptive technologies starting with the application of innovative learning technologies, such as massive open online courses [100] or serious games [30], augmented reality and mobile devices [33], or the growing level of automation due to artificial intelligence and robotization [31]; surmounting barriers like cultural divide in terms of those who do and those who do not (do recycle, do not use plastic bags) [24], or enduring loss from wrong beliefs (e.g., the impact of "alternative facts" or "fake news" in driving real news, together with low trust in media or the increasing presence of fake indicators, etc.) [101].

The content of clusters also uncovered stringent topics that are not dealt with enough in the literature. For example, in the cluster "integrating sustainability", we found "indigenous knowledge", a topic that, although not frequently approached, is deemed by UNESCO as a key-concept to SD. "Indigenous knowledge (IK) is broadly speaking, the knowledge used by local people to make a living in a particular environment. ... This definition encompasses all forms of knowledge, technologies, know-how skills, practices and beliefs that enable the community to achieve stable livelihoods in their environment" [102].

In our dataset, there were 15 articles about IK, written between 2009 and 2018, with an average of two articles per year. Most of them had Canadian authors. Despite the fact that Canada's educational institutions have largely ignored, and continue to ignore, IK and pedagogy [103], Canada is still one of the first countries that recognizes IK as a valuable asset the world can use to better understand climate impacts. In these papers, the authors described IK practices and approaches and their utilization pattern for SD, as well as the challenges and opportunities in the protection and preservation of IK in different parts of the world. They dealt less with how to integrate IK in classroom lessons and in the curriculum. Indigenous knowledge, as an important connection to sustainability [62], alongside many other trends that are waiting to be discovered, is a growing field of inquiry; therefore, researchers should be prepared to further investigate other aspects like: What is the teachers' understanding of the nature of IK? To what extent do they integrate IK in the classroom? What are their reasons for not including IK in the classroom? 
To sum up the keywords' analysis, we should note that by identifying research areas and emerging trends, we have confirmation, once again, that ESD studies have increased rapidly and that ESD issues are interdisciplinary and extremely complex.

\subsection{Limits and Suggestions for Further Research}

The data we analyzed provided interesting insights on research in ESD carried out since 1992 up to the present. Nevertheless, there are some limitations that should be acknowledged:

- Firstly, our study was based on a sample of documents from WoS. There are other databases that index papers on ESD that should be explored. As we have seen in Table 3, Scopus and Google Scholar offer for the most cited authors more documents than WoS. Tăbăcaru [104] reported that at the beginning of the year 2019, Scopus had 31\% more indexed journals than WoS. In a recent study, Martin et al. [37] asserted that Google Scholar will be a better source than WoS or Scopus in terms of comprehensive coverage and finding significant citations. However, scholars might consider conducting bibliometric analyses using other databases, maybe even making comparisons between them [85]. On the other hand, due to terminological innovations, variations, or linguistic confusion, articles that are relevant to ESD might exist, even though they have not been covered by this bibliometric study. Consequently, we believe further bibliometric investigations are necessary, so that we make sure a complete (as far as possible) dataset is obtained and then analyzed. In order to avoid duplicates or names with diacritics, apostrophes or ligatures, Thesaurus in VosViewer could be used.

- Secondly, it is well known that WoS includes, almost exclusively, documents published in English. Although the WoS Core Collection also comprises non-English journals or literature (with the non-English titles translated into English), the number of publications in other languages is much lower. In their study about promoting sustainability in HE in Portuguese speaking countries, Bizerril et al. [105] searched the SciELO (Scientific Electronic Library Online) database as well, showing that the number of papers on the topic was much bigger in Portuguese than in English provided by WoS. Thus, an analysis on non-English language databases would be interesting to do. Furthermore, as our results showed, the non-anglophone countries and cultures have different perspectives on ESD (with the notable impact of Chinese literature). More and more often, documents written in vernacular languages (which usually address locally or regionally relevant topics) cite non-English literature. This has a direct influence on the citation coverage of documents.

- Thirdly, by analyzing the WoS dataset, for the period of 1992-2018, we gained a general view of the ESD field, because the impact of documents, authors, and journals changes over time. Although the citation indicator is not exhaustive, it is quite objective and is widely used to assess the performance of scientific research. However, this indicator only calculates citations of published papers; informal communication, the exchange of ideas, and their contribution to the configuration of a scientific work are not taken into consideration.

- Another limitation refers to the level of interest generated by an author's work. Despite the fact that in WoS, we have the "Usage counts" function, in this study, we did not consider the degree of visualization and the number of downloads in a bibliographic management tool; nor did we use alternative or complementary metrics for disseminating and tracking research. For instance, influence on social media (tweets about an article, journals comments, research blogs, Facebook posts, Wikipedia pages etc.) can be tracked by tools such as Altmetric. We did not include the type of papers in the set, either. Are they literature review, essays, conceptual papers, theoretical, or empirical studies? This is more a shortcoming of the method than a limitation of our study, but future systematic and qualitative reviews might be able to incorporate these aspects, as well.

- As we have seen, there are emerging research trends or certain sub-fields that are less researched (e.g., IK) and are awaiting contributions (e.g., the importance of new technologies and applications 
in ESD, like serious games, artificial intelligence, Internet of Things, or blockchain). Thus, we could add to further studies more detailed bibliometric analyses of some of the clusters and themes/topics detected in this work.

- Finally, the chosen timespan (1992-2018) should be reassessed by similar future research. In other words, the study should be reapplied and expanded, to keep up-to-date with new developments in the field and to see what differences occur between one period to the next.

However, these limitations can be seen as challenges that are opening up new avenues for future research.

\section{Conclusions}

In this article, we carried out a bibliometric analysis on 1813 papers published in the field of ESD. The papers were retrieved from the WoS database and covered the timeframe of 1992-2018. The main findings increased our understanding of the ESD domain: we identified vital research, landmark studies in the development of the field, critical past contributions, emerging trends, and potentially transformative ideas.

The number of publications, authors, and journals has increased, proving that ESD has gained momentum over the period examined in the study. Similarly, there are more and more works written in collaboration by people from different parts and cultures of the world, indicating that publishing on ESD is like a legacy to international efforts to bring this area of inquiry into the mainstream.

Basically, for the entire timespan we analyzed, the two main research directions were observed: integration of education into sustainable development and of sustainable development into education.

To conclude, we would like to stress once more the importance of bibliometric analysis in: (a) evaluating the international influence of scientific work in a reliable, transparent, and objective manner, in diverse research trends of ESD; (b) creating maps for scientific domains revealing the transnational and interdisciplinary character of ESD.

Starting from the most well known standard used to report sustainable development for organizations (Global Reporting Initiative), established by the NGO with the same name, together with the UN Program for the Environment, we adopted some principles of quality analysis and adapted them for the purposes of our study:

- Originality: Our study's main contribution resides in the fact that we analyzed the entire period starting with the year in which ESD was defined as a research concept and up to the present. We also extended the range of indicators that are normally being used in bibliometric studies. Moreover, by employing three search terms, we managed to identify new research topics (e.g., IK) that are less visible, but equally important for solving specific ESD issues.

- Balance: Our current work illustrated both the positive aspects of our research and the limitations, so that scholars interested in this subject might come to an accurate evaluation of our activity and undertake further studies starting from our limitations and the Discussions Section.

- Comparability: We selected, collected, and included in this study information that allows those who might be interested to look at the evolution of the field (ESD), to identify countries, organizations, authors, and emergent trends, and at the same time, to make comparisons with other studies on the topic.

- Accuracy: The information included in this document was extracted from WoS, the biggest database of abstracts and citations for scientific literature. Therefore, we considered the data to be correct, up-to-date, and accurate.

- Clarity: We chose to present the information we obtained by bibliometric analysis and visualization (mapping science) so it could be accessible and easy to understand.

- Timeliness: Our intention is to replicate this analysis in the following years because the field appears to be highly dynamic. All those responsible for policies, organization managers, but also 
young researchers and/or PhD students, need to be well informed on the developments in order to be able to make the appropriate decisions.

Despite all the results of the research carried out until now, there is still a long journey ahead, but we are convinced that ESD research is moving in the right direction.

Author Contributions: The authors collaborated on all parts of this review (including designing, collecting the data, the analysis of the documents, and writing the results). All authors read and approved the final manuscript.

Funding: This research received no external funding.

Conflicts of Interest: The authors declare no conflict of interest.

\section{References}

1. Wright, T.; Pullen, S. Examining the Literature: A Bibliometric Study of ESD Journal Articles in the Education Resources Information Center Database. J. Educ. Sustain. Dev. 2007, 1, 77-90. [CrossRef]

2. Reunamo, J.; Pipere, A. Doing research on education for sustainable development. Int. J. Sustain. High. Educ. 2011, 12, 110-124. [CrossRef]

3. Hassan, S.U.; Haddawy, P.; Zhu, J. A bibliometric study of the world's research activity in sustainable development and its sub-areas using scientific literature. Scientometrics 2014, 99, 549-579. [CrossRef]

4. Côrtes, P.L.; Rodrigues, R. A bibliometric study on "education for sustainability". Braz. J. Sci. Technol. 2016, 3, 8. [CrossRef]

5. Cullen, J.G. Educating Business Students About Sustainability: A Bibliometric Review of Current Trends and Research Needs. J. Bus. Ethics 2017, 145, 429-439. [CrossRef]

6. Zhu, J.; Hua, W.J. Visualizing the knowledge domain of sustainable development research between 1987 and 2015: A bibliometric analysis. Scientometrics 2017, 110, 893-914. [CrossRef]

7. Veiga Ávila, L.; Rossato Facco, A.L.; Bento, M.H.D.S.; Arigony, M.M.; Obregon, S.L.; Trevisan, M. Sustainability and education for sustainability: An analysis of publications from the last decade. Environ. Qual. Manag. 2018, 27, 107-118. [CrossRef]

8. Trindade, N.R.; Marques, C.S.; Piveta, M.N.; Favarin, R.R.; Telocken, S.G.; Trevisan, M. Education for sustainability and learning theories: A bibliometric study for the last 10 years. Braz. J. Manag. 2018, 11, 19. [CrossRef]

9. Zutshi, A.; Creed, A.; Connelly, B.L. Education for Sustainable Development: Emerging Themes from Adopters of a Declaration. Sustainability 2019, 11, 156. [CrossRef]

10. Tang, M.; Liao, H.C.; Wan, Z.J; Herrera-Viedma, E.; Rosen, M.A. Ten Years of Sustainability (2009 to 2018): A Bibliometric Overview. Sustainability 2018, 10, 1655. [CrossRef]

11. WCED. Our Common Future; 1987; p. 300. Available online: https://sustainabledevelopment.un.org/content/ documents/5987our-common-future.pdf (accessed on 12 April 2019).

12. European Commission. EU Approach to Sustainable Development. Available online: https://ec.europa.eu/info/strategy/international-strategies/sustainable-development-goals/eu-approachsustainable-development_en (accessed on 23 March 2019).

13. Sarabhai, K.V. ESD and Global Citizenship Education. J. Educ. Sustain. Dev. 2013, 7, 137-139. [CrossRef]

14. Sterling, S. A Commentary on Education and Sustainable Development Goals. J. Educ. Sustain. Dev. 2016, 10, 208-213. [CrossRef]

15. Nations, U. Education Commitments Agenda 21-Chapter 36 \& UN Commission on Sustainable Development. 1992. Available online: https://www.iatp.org/sites/default/files/Education_Commitments_-_Agenda_21_ Chapter_36.htm (accessed on 25 May 2019).

16. Boeve-de Pauw, J.; Gericke, N.; Olsson, D.; Berglund, T. The Effectiveness of Education for Sustainable Development. Sustainability 2015, 7, 15693-15717. [CrossRef]

17. Kishita, Y.; Uwasu, M.; Hara, K.; Kuroda, M.; Takeda, H.; Umeda, Y.; Shimoda, Y. Toward designing sustainability education programs: A survey of master's programs through semi-structured interviews. Sustain. Sci. 2018, 13, 953-972. [CrossRef]

18. UNESCO. ESD-Building a Better, Fairer World for the 21st Century. 2013. Available online: http: //u4614432.fsdata.se/wp-content/uploads/2013/09/esd.pdf (accessed on 4 April 2019). 
19. Goian, C. Ten Categories of Inconsequentialities from the Romanian Social Work Language. Rev. Asistență Soc. 2010, 1, 79-90.

20. Van Poeck, K.; Jürgen, L. Education for Sustainable Development: Flag and Cargo; Flemish Government, Environment, Nature and Energy Department: Brussels, Belgium, 2011.

21. Lambrechts, W.; Hindson, J. Education for Sustainable Development in a complex and changing world. In Research and Innovation in Education for Sustainable Development. Exploring Collaborative Networks, Critical Characteristics and Evaluation practices; Lambrechts, W., Hindson, J., Eds.; Environment and School Initiatives -ENSI: Vienna, Austria, 2016; pp. 6-10.

22. Vezzani, V.; Gonzaga, S. Design for Social Sustainability. An educational approach for insular communities. Des. J. 2017, 20, S937-S951. [CrossRef]

23. Hassan, R.; Mungatana, E.; Akpalu, W. Strategies for Managing Common Pool Natural Resources in Sub-Saharan Africa: A Review of Past Experience and Future Challenges. Rev. Environ. Econ. Policy 2019, 13, 207-226. [CrossRef]

24. Dahms, T.; McMartin, D.W.; Petry, R.A. Overcoming Traditional Boundaries in Advancing Education for Sustainable Development. In Handbook of Theory and Practice of Sustainable Development in Higher Education; Filho, L., Brandli, L.L., Castro, P., Newman, J., Eds.; Springer International Publishing: Cham, Switzerland, 2017; Volume 4, pp. 111-124.

25. Rampasso, I.S.; Siqueira, R.G.; Anholon, R.; Silva, D.; Quelhas, O.L.G.; Leal, W.; Brandli, L.L. Some of the challenges in implementing Education for Sustainable Development: Perspectives from Brazilian engineering students. Int. J. Sustain. Dev. World Ecol. 2019, 26, 367-376. [CrossRef]

26. Tamara, S. Sustainable schooling in the Asia-Pacific region. In Routledge International Handbook of Schools and Schooling in Asia; Routledge: Abingdon-on-Thames, UK, 2018.

27. McGreal, R. Special Report on the Role of Open Educational Resources in Supporting the Sustainable Development Goal 4: Quality Education Challenges and Opportunities. Int. Rev. Res. Open Distrib. Learn. 2017, 18, 292-305. [CrossRef]

28. Tovar, E.; Tabuenca, B.; Alzaghoul, A.; Kloos, C.D.; Sluss, J.; López-Rey, Á.; Ruiz, E.; García-Loro, F.; Sancristóbal, E.; Artacho, M.R.; et al. Do MOOCs Sustain the UNESCO's Quality Education Goal? In Proceedings of the 2019 IEEE Global Engineering Education Conference (EDUCON), Dubai, UAE, 8-11 April 2019; pp. 1499-1503.

29. Buil-Fabregá, M.; Martínez Casanovas, M.; Ruiz-Munzón, N.; Leal Filho, W. Flipped Classroom as an Active Learning Methodology in Sustainable Development Curricula. Sustainability 2019, 11, 4577. [CrossRef]

30. Ouariachi, T.; Olvera-Lobo, M.D.; Gutiérrez-Pérez, J. Serious Games and Sustainability. In Encyclopedia of Sustainability in Higher Education; Springer International Publishing: Cham, Switzerland, 2018; pp. 1-10.

31. Park, I.W.; Han, J. Teachers' views on the use of robots and cloud services in education for sustainable development. Clust. Comput.-J. Netw. Softw. Tools Appl. 2016, 19, 987-999. [CrossRef]

32. Palaigeorgiou, G.; Malandrakis, G.; Tsolopani, C. Learning with Drones: Flying windows for classroom virtual field trips. In Proceedings of the 17th IEEE International Conference on Advanced Learning Technologies (ICALT), Politehnica Univ Timisoara, Timisoara, Romania, 3-7 July 2017; pp. 338-342.

33. Velazquez, F.D.; Mendez, G.M. Augmented Reality and Mobile Devices: A Binominal Methodological Resource for Inclusive Education (SDG 4). An Example in Secondary Education. Sustainability 2018, 10, 3446. [CrossRef]

34. Stevenson, R.B.; Brody, M.; Dillon, J.; Wals, A.E.J. International Handbook of Research on Environmental Education; Routledge: New York, NY, USA, 2013; p. 592.

35. Liao, H.C.; Tang, M.; Luo, L.; Li, C.Y.; Chiclana, F.; Zeng, X.J. A Bibliometric Analysis and Visualization of Medical Big Data Research. Sustainability 2018, 10, 166. [CrossRef]

36. Ellegaard, O.; Wallin, J.A. The bibliometric analysis of scholarly production: How great is the impact? Scientometrics 2015, 105, 1809-1831. [CrossRef] [PubMed]

37. Martin-Martin, A.; Orduna-Malea, E.; Thelwall, M.; Lopez-Cozar, E.D. Google Scholar, Web of Science, and Scopus: A systematic comparison of citations in 252 subject categories. J. Informetr. 2018, 12, 1160-1177. [CrossRef]

38. Bornmann, L.; Marx, W. How good is research really? Measuring the citation impact of publications with percentiles increases correct assessments and fair comparisons. EMBO Rep. 2013, 14, 226-230. [CrossRef] 
39. Fox, C.W.; Paine, C.E.T.; Sauterey, B. Citations increase with manuscript length, author number, and references cited in ecology journals. Ecol. Evol. 2016, 6, 7717-7726. [CrossRef]

40. Eom, Y.H.; Fortunato, S. Characterizing and Modeling Citation Dynamics. PLoS ONE 2011, 6, e24926. [CrossRef]

41. Glanzel, W. Analysis of co-authorship patterns at the individual level. Transinformacao 2014, 26, 229-238. [CrossRef]

42. Roemer, R.C.; Borchardt, R. Meaningful Metrics: A 21st Century Librarian's Guide to Bibliometrics, Altmetrics, and Research Impact; Association of College and Research Libraries: Chicago, IL, USA, 2015; p. 251.

43. Carley, S.; Porter, A.L.; Rafols, I.; Leydesdorff, L. Visualization of Disciplinary Profiles: Enhanced Science Overlay Maps. J. Data Inf. Sci. 2017, 2, 68-111. [CrossRef]

44. Abramo, G.; D'Angelo, C.; Viel, F. The suitability of $\mathrm{h}$ and $\mathrm{g}$ indexes for measuring the research performance of institutions. Scientometrics 2013, 97, 555-570. [CrossRef]

45. Haustein, S.; Larivière, V. The Use of Bibliometrics for Assessing Research: Possibilities, Limitations and Adverse Effects. In Incentives and Performance: Governance of Research Organizations; Springer International Publishing: Cham, Switzerland, 2015; pp. 121-139.

46. van Eck, N.J.; Waltman, L. Visualizing Bibliometric Networks. In Measuring Scholarly Impact: Methods and Practice; Springer International Publishing: Cham, Switzerland, 2014; pp. 285-320.

47. Chen, C. CiteSpace: A Practical Guide for Mapping Scientific Literature; UK ed. edition; NovaPublisher: Hauppauge, NY, USA, 2016.

48. Albort-Morant, G.; Henseler, J.; Leal-Millan, A.; Cepeda-Carrion, G. Mapping the Field: A Bibliometric Analysis of Green Innovation. Sustainability 2017, 9, 1011. [CrossRef]

49. Todeschini, R.; Alberto, B. Handbook of Bibliometric Indicators. Quantitative Tools for Studying and Evaluating Research; Wiley-VCH Verlag GmbH \& Co. KgaA: Weinheim, Germany, 2016.

50. Pradhan, P. Science Mapping and Visualization Tools used in Bibliometric \& Scientometric Studies: An Overview. Inflibnet 2016, 23, 19-33.

51. Perianes-Rodriguez, A.; Waltman, L.; van Eck, N.J. Constructing bibliometric networks: A comparison between full and fractional counting. J. Informetr. 2016, 10, 1178-1195. [CrossRef]

52. Garrigos-Simon, F.J.; Narangajavana-Kaosiri, Y.; Lengua-Lengua, I. Tourism and Sustainability: A Bibliometric and Visualization Analysis. Sustainability 2018, 10, 1976. [CrossRef]

53. Davis, S.; Roberts, J. A Bibliometric Analysis of Articles Supported by NOAA's Office of Ocean Exploration and Research; Commerce, U.D.O., Ed.; NOAA Central Library, 2019. Available online: https://oceanexplorer.noaa. gov/data/publications/media/oer-citation-report-feb2019.pdf (accessed on 17 March 2019).

54. Hallinger, P.; Chatpinyakoop, C. A Bibliometric Review of Research on Higher Education for Sustainable Development, 1998-2018. Sustainability 2019, 11, 2401. [CrossRef]

55. Briggs, L.; Trautmann, N.M.; Fournier, C. Environmental education in Latin American and the Caribbean: The challenges and limitations of conducting a systematic review of evaluation and research. Environ. Educ. Res. 2018, 24, 1631-1654. [CrossRef]

56. Nomura, K. A perspective on education for sustainable development: Historical development of environmental education in Indonesia. Int. J. Educ. Dev. 2009, 29, 621-627. [CrossRef]

57. Maurer, M.; Bogner, F.X. How freshmen perceive Environmental Education (EE) and Education for Sustainable Development (ESD). PLoS ONE 2019, 14, e0208910. [CrossRef]

58. Reid, A.; Scott, W. Researching education and the environment: Retrospect and prospect. Environ. Educ. Res. 2006, 12, 571-587. [CrossRef]

59. Rickinson, M. Reviewing Research Evidence in Environmental Education: Some methodological reflections and challenges. Environ. Educ. Res. 2003, 9, 257-271. [CrossRef]

60. Gong, R.F.; Xue, J.; Zhao, L.J.; Zolotova, O.; Ji, X.Q.; Xu, Y. A Bibliometric Analysis of Green Supply Chain Management Based on the Web of Science (WOS) Platform. Sustainability 2019, 11, 3459. [CrossRef]

61. Moher, D.; Liberati, A.; Tetzlaff, J.; Altman, D.G.; Grp, P. Preferred Reporting Items for Systematic Reviews and Meta-Analyses: The PRISMA Statement. PLoS Med. 2009, 6, e1000097. [CrossRef] [PubMed]

62. Aikens, K.; McKenzie, M.; Vaughter, P. Environmental and sustainability education policy research: A systematic review of methodological and thematic trends. Environ. Educ. Res. 2016, 22, 333-359. [CrossRef]

63. Wang, W. An Exploration of Patterns in the Practice of Education for Sustainable Development in China: Experience and Reflectio. Open J. Soc. Sci. 2015, 3, 64-75. [CrossRef] 
64. Rosas, S.R.; Kagan, J.M.; Schouten, J.T.; Slack, P.A.; Trochim, W.M.K. Evaluating Research and Impact: A Bibliometric Analysis of Research by the NIH/NIAID HIV/AIDS Clinical Trials Networks. PLoS ONE 2011, 6, e17428. [CrossRef] [PubMed]

65. Waltman, L.; Schreiber, M. On the calculation of percentile-based bibliometric indicators. J. Am. Soc. Inf. Sci. Technol. 2013, 64, 372-379. [CrossRef]

66. Tahamtan, I.; Bornmann, L. What Do Citation Counts Measure? An Updated Review of Studies on Citations in Scientific Documents Published between 2006 and 2018. arXiv 2019, arXiv:1906.04588. [CrossRef]

67. Mazloumian, A.; Eom, Y.H.; Helbing, D.; Lozano, S.; Fortunato, S. How Citation Boosts Promote Scientific Paradigm Shifts and Nobel Prizes. PLoS ONE 2011, 6, e18975. [CrossRef]

68. Glanzel, W. Bibliometric Methods for Detecting and Analysing Emerging Research Topics. El Profesional de la Información 2012, 21, 194-201. [CrossRef]

69. Xiao, X.; Skitmore, M.; Li, H.; Xia, B. Mapping Knowledge in the Economic Areas of Green Building Using Scientometric Analysis. Energies 2019, 12, 3011. [CrossRef]

70. UNESCO. UN Decade of Education for Sustainable Development. Links between the Global Initiatives in Education; 2005; p. 27. Available online: https://sustainabledevelopment.un.org/ (accessed on 18 June 2019).

71. Fazey, J.; Schapke, N.; Caniglia, G.; Patterson, J.; Hultman, J.; van Mierlo, B.; Saawe, F.; Wiek, A.; Wittmayer, J.; Aldunce, P.; et al. Ten essentials for action-oriented and second order energy transitions, transformations and climate change research. Energy Res. Soc. Sci. 2018, 40, 54-70. [CrossRef]

72. Rieckman, M. Key themes in Education for Sustainable Development. In Issues and Trends in Education for Sustainable Development; Leicht, A., Heiss, J., Byun, W.J., Eds.; UNESCO Publishing: Paris, France, 2018; pp. 61-87.

73. Malone, K.; Somerville, M. Education for Sustainable Development Report 2015 Contribution to Quality Education in Australian Schools; Western Sydney University, Centre for Educational Research: Penrith, Australia, 2015; p. 52.

74. Roy, A.; Suhonen, J.; Kihoza, P.; Vesisenaho, M. Promoting Education for Sustainable Development by using ICT enhanced Problem Based Learning in a developing country. In Proceedings of the 2012 IEEE Fourth International Conference on Technology for Education, Hyderabad, India, 18-20 July 2012; pp. 98-104.

75. Schulte, C.; Kruger, J.; Godecke, A.; Schmidt, A.K. The Computing Repair Cafe A Concept for Repair cafes in Computing edcuation. In Proceedings of the 13th Workshop in Primary and Secondary Computing Education, Potsdam, Germany, 4-6 October 2018; pp. 127-132.

76. Makrakis, V. ICTs in Education for Sustainable Development. Available online: http: //www.unescobkk.org/education/ict/online-resources/databases/ict-in-education-database/item/article/ictsin-education-for-sustainable-development/ (accessed on 21 March 2019).

77. Sachs, J.D.; Schmidt-Traub, G.; Kroll, C.; Lafortune, G.; Fuller, G. Sustainable Development Report 2019; Bertelsmann Stiftung and Sustainable Development Solutions Network (SDSN): New York, NY, USA, 2019.

78. Zhang, N.; Wang, B. Toward a Sustainable Low-Carbon China: A Review of the Special Issue of "Energy Economics and Management". Sustainability 2016, 8, 823. [CrossRef]

79. Min, W.; Dongying, W. Education for Sustainable Development in China: A Perspective on Curricula Standards and Geography Textbooks. Int. Schulb. 2007, 29, 185-197.

80. Niu, D.J.; Jiang, D.H.; Li, F.T. Higher education for sustainable development in China. Int. J. Sustain. High. Educ. 2010, 11, 153-162. [CrossRef]

81. Ting, W. Education for Sustainable Development in China. J. Sustain. Educ. 2014, 6. Available online: http://www.jsedimensions.org/wordpress/wp-content/uploads/2014/05/Wang-Ting-JSE-May-2014PDF-Ready.pdf. (accessed on 2 November 2019).

82. OECD. Active with the People's Republic of China; OECD: Paris, France, 2018; p. 68.

83. Mohanty, A. Education for sustainable development: A conceptual model of sustainable education for India. Int. J. Dev. Sustain. 2018, 7, 2242-2255.

84. Alba-Hidalgo, D.; del Alamo, J.B.; Gutierrez-Perez, J. Towards a Definition of Environmental Sustainability Evaluation in Higher Education. High. Educ. Policy 2018, 31, 447-470. [CrossRef]

85. Harzing, A.-W. Google Scholar as a new data source for citation analysis. In Research in International Management, 8th ed.; Harzing.com, 2019; Volume 2019, Available online: https://harzing.com/publications/ white-papers/google-scholar-a-new-data-source-for-citation-analysis (accessed on 2 November 2019). 
86. Mogensen, F.; Schnack, K. The action competence approach and the 'new' discourses of education for sustainable development, competence and quality criteria. Environ. Educ. Res. 2010, 16, 59-74. [CrossRef]

87. Brundiers, K.; Wiek, A.; Redman, C. Real-world learning opportunities in sustainability: From classroom into the real world. Int. J. Sustain. High. Educ. 2010, 11, 308-324. [CrossRef]

88. Wiek, A.; Withycombe, L.; Redman, C. Key competencies in sustainability: A reference framework for academic program development. Sustain. Sci. 2011, 6, 203-218. [CrossRef]

89. Rieckmann, M. Future-oriented higher education: Which key competencies should be fostered through university teaching and learning? Futures 2012, 44, 127-135. [CrossRef]

90. Steiner, G.; Posch, A. Higher education for sustainability by means of transdisciplinary case studies: An innovative approach for solving complex, real-world problems. J. Clean. Prod. 2006, 14, 877-890. [CrossRef]

91. Christensen, L.; Peirce, E.; Hartman, L.; Hoffman, W.; Carrier, J. Ethics, CSR, and sustainability education in the Financial times top 50 global business schools: Baseline data and future research directions. J. Bus. Ethics 2007, 73, 347-368. [CrossRef]

92. Jickling, B.; Wals, A. Globalization and environmental education: Looking beyond sustainable development. J. Curric. Stud. 2008, 40,1-21. [CrossRef]

93. Barth, M.; Rieckmann, M. Academic staff development as a catalyst for curriculum change towards education for sustainable development: An output perspective. J. Clean. Prod. 2012, 26, 28-36. [CrossRef]

94. Lozano, R.; Lukman, R.; Lozano, F.; Huisingh, D.; Lambrechts, W. Declarations for sustainability in higher education: Becoming better leaders, through addressing the university system. J. Clean. Prod. 2013, 48, 10-19. [CrossRef]

95. Lozano, R.; Ceulemans, K.; Alonso-Almeida, M.; Huisingh, D.; Lozano, F.; Waas, T.; Lambrechts, W.; Lukman, R.; Huge, J. A review of commitment and implementation of sustainable development in higher education: Results from a worldwide survey. J. Clean. Prod. 2015, 108, 1-18. [CrossRef]

96. Moore, D.; Almeida, S.C.; Barnes, M. Education for Sustainability Policies: Ramifications for Practice. Aust. J. Teach. Educ. 2018, 43. [CrossRef]

97. Seglen, P.O. Why the impact factor of journals should not be used for evaluating research. BMJ 1997, 314, 497. [CrossRef]

98. Jarneving, B. Bibliographic coupling and its application to research-front and other core documents. J. Informetr. 2007, 1, 287-307. [CrossRef]

99. Kopnina, H. Circular economy and Cradle to Cradle in educational practice. J. Integr. Environ. Sci. 2018, 15, 123-138. [CrossRef]

100. Latchem, C. Education for Sustainable Development. In Open and Distance Non-formal Education in Developing Countries; Springer: Singapore, 2018; pp. 155-165.

101. Bell, S.; Morse, S. Sustainability Indicators Past and Present: What Next? Sustainability 2018, $10,1688$. [CrossRef]

102. UNESCO. Local Knowledge, Global Goals; 2017; p. 46. Available online: https://en.unesco.org/lik-expo (accessed on 9 February 2019).

103. Battiste, M. Indigenous knowledge and indigenous peoples' education. In Traditional Knowledge in Policy and Practice: Approaches to Development and Human Well-Being; Suneetha, M.S., Pisupati, B., Eds.; UNU Press: Tokyo, Japan, 2010; pp. 31-52.

104. Tăbăcaru, S. Web of Science Versus Scopus: Journal Coverage Overlap Analysis; Texas A\&M University Libraries: Killeen, TX, USA, 2019.

105. Bizerril, M.; Rosa, M.; Carvalho, T.; Pedrosa, J. Sustainability in higher education: A review of contributions from Portuguese Speaking Countries. J. Clean. Prod. 2018, 171, 600-612. [CrossRef]

(C) 2019 by the authors. Licensee MDPI, Basel, Switzerland. This article is an open access article distributed under the terms and conditions of the Creative Commons Attribution (CC BY) license (http://creativecommons.org/licenses/by/4.0/). 